\title{
Multiple myeloma: the disease and its treatment
}

\author{
Meenakshi Gupta $^{\mathrm{a} *}$, Rana Arun Gopal Krishan Pal $^{\mathrm{b}}$, Deepika Tikoo ${ }^{\mathrm{a}}$
}

\begin{abstract}
${ }^{a}$ Department of Pharmacology, Sri Guru Ram Das Institute of Medical sciences and Research, Vallah, Amritsar-143001, Punjab, India, ${ }^{\mathrm{b}}$ Department of Pathology, Genesis Institute of Dental Sciences \& Research, Ferozepur-152002, Punjab, India
\end{abstract}

Received: 23 January 2013

Accepted: 27 January 2013

\section{*Correspondence to:}

Dr. Meenakshi Gupta,

Email: dr.meenakshipal@gmail.com

\section{(C) 2013 Gupta $\mathrm{M}$ et al. This is an} open-access article distributed under the terms of the Creative Commons Attribution License, which permits unrestricted use, distribution, and reproduction in any medium, provided the original work is properly cited.

\begin{abstract}
Multiple myeloma represents a malignant proliferation of plasma cells derived from a single clone. The tumor, its products and the host response to it result in a number of organ dysfunctions and symptoms of bone pain, fracture, anemia, hypercalcemia, susceptibility to infection, neurologic symptoms, clotting abnormalities and manifestations of hyperviscosity. The cause of myeloma remains unexplained but it is associated with few occupations, inflammatory conditions, autoimmune illnesses, viral infections and genetic heterogeneity. Direct interaction between multiple myeloma cells and bone marrow cells activates pleiotropic signalling pathways that mediate growth, survival, migration of multiple myeloma cells and also resistance to chemotherapy. Although myeloma remains incurable, but the use of novel drugs like thalidomide, lenalidomide and bortezomib have resulted in a paradigm change in the therapy of myeloma. Their inclusion in current multiple myeloma treatment regimens have extended median overall survival especially in younger patient population. Recent advances in the molecular genetics have provided opportunities to design highly specific inhibitors of signal transduction pathways that may enhance the efficacy of standard chemotherapy drugs by reducing or altering the pathways associated with cell survival. Despite therapeutic advances, multiple myeloma ultimately relapses and remains an incurable disease. Current research goals are to further increase our knowledge, to identify additional targeted therapies, and to reduce adverse effects and improve response rate. This review focuses on recent clinical advancement in ant myeloma strategies with additional discussion dedicated to emerging drugs that may prove beneficial to patients with this disease.
\end{abstract}

Keywords: Myeloma, Thalidomide, Lenalidomide, Bortezomib, Therapy

\section{INTRODUCTION}

Multiple Myeloma (MM) though lowest in developing countries including Asia, is highest in African-American and Pacific islanders; intermediate in Europeans and North American Caucasians. The higher incidence in more developed countries may result from the combination of a longer life expectancy, more frequent medical surveillance and due to heightened awareness of the disease. ${ }^{1}$ Myeloma accounts for $13 \%$ of all the hematologic malignancies and $2 \%$ of all the malignant diseases. The incidence of myeloma is around 1-9 per 100,000 per year worldwide with higher incidence in North America 7.1 per 100,000 per year. ${ }^{2,3}$ Myeloma increases in incidence with age. The median age at diagnosis is 62-65years in industrialized nations and is about a decade less in developing countries (median age in India is 55-56years). ${ }^{2-4}$ About 14,400 cases of MM are diagnosed each year, and 11,200 deaths were recorded in the United States in $2001^{5}$ and in 2007, 19,900 cases were diagnosed while 10,790 deaths were recorded in United States. ${ }^{1}$ Median survival is $50-55$ months. ${ }^{6}$ The male to female ratio is higher $1.2-1.5: 1^{4,7}$ Despite these differences in prevalence, the characteristics, response to therapy and prognosis of myeloma are similar worldwide. $^{1}$

The term multiple myeloma (from Gk. Myelo-, bone marrow), was coined in 1873 by Von Rustizky. ${ }^{8}$ It is also known as plasma cell myeloma, or as Kahler's disease (after Otto Kahler). ${ }^{9}$ Myeloma is an accumulation of malfunctioning or cancerous plasma cells. Despite the name myeloma, this form of cancer does not involve myeloid cells, as plasma cells are lymphoid, but is so named because it mainly involves the myelum (bone marrow). Most plasma cells reside in the bone marrow, 
and myeloma, usually occurs within the marrow of large bones of the body, such as the skull, vertebrae (spine), and hips. Plasma cells that have undergone malignant transformation do so in clumps and usually at many sites, which explains the terminology "multiple myeloma." The net effect is the appearance of large numbers of abnormal cells capable of forming bodily masses, or tumors, with the capacity to advance locally and invade adjacent tissues and organs or spread either through the lymphatics or the blood vessels into distant organs. ${ }^{10}$

\section{ETIOPATHOGENESIS}

The cause of MM remains unexplained. Myeloma occurred with increased frequency in those exposed to the radiation of nuclear warheads in World War II after 20year latency. ${ }^{1}$ It has been seen more commonly among farmers, ${ }^{11}$ wood workers, leather workers, those exposed to petroleum products and radiation related occupations. ${ }^{12}$ Several studies have suggested that myeloma risk is associated with past history of infections, ${ }^{13}$ inflammatory conditions, connective tissue disorders, autoimmune illnesses and allergy related disorder. In addition $\mathrm{MM}$ and viral infection like HIV ${ }^{14}$, Hepatitis $\mathrm{C}^{15}$ and Herpesvirus $8^{16}$ may also be associated. There is considerable genetic heterogeneity among patients of MM that impacts disease progression and response to therapy. A variety of chromosomal aberrations like del(13q14) $\mathrm{t}(11 ; 14)(\mathrm{q} 13 ; \mathrm{q} 32), \quad \mathrm{t}(4 ; 14)(\mathrm{p} 16 ; \mathrm{q} 32), \quad$ MYC rearrangements, hyperdiploidy, and $\operatorname{del}(17 \mathrm{p} 13)$ has been noted. $^{17}$

A causal relationship between monoclonal gammopathy of undetermined significance (MGUS) or MM and chronic antigenic stimulation has been suggested. ${ }^{18}$ A 2-3 fold higher risk of developing MGUS or MM has been reported in family members of patients with MGUS or MM. ${ }^{19,20}$ MGUS is considered to be initial event in the pathogenesis of myeloma. MGUS is a premalignant condition that may progress to smoldering multiple myeloma (SMM), and ultimately symptomatic intramedullary or extra medullary myeloma or plasma cell leukemia. The risk of progression of MGUS to multiple myeloma- related disorder is thus approximately $1 \%$ per year. $^{21}$

The neoplastic event in myeloma may involve cells earlier in B-cell differentiation than the plasma cell. When B-lymphocytes are made by bone marrow, they are stimulated by antigen in the lymph node into two kinds of plasma cells, the pregerminal center plasma cell (Pre GCPC) and the postgerminal center plasma cell (post GCPC). Pre GCPC is usually short lived. In contrast post GCPC are long lived and they migrate to bone marrow. Multiple myeloma is tumor of post GCPC. In myeloma, tumor cells are mainly localized in bone marrow microenvironment. ${ }^{22}$

Bone marrow endothelial cells (BMECs) and stromal cells (BMSCs) secrete a variety of chemokines such as stromal-derived factor 1 (SDF-1) and insulin-like growth factor 1 (IGF-1) that serve as chemoattractants for MM cells. Multiple myeloma cell binds to bone marrow cell, which stimulates the production of various cytokines like interleukin (IL)-6, Interferon gamma (IFN- $\gamma$ ), vascular endothelial growth factor (VEGF), tumor necrosis factors (TNFs), transforming growth factor- $\beta$ (TGF- $\beta$ ), and receptor activator of nuclear factor- $\kappa \mathrm{B}$ ligand (RANKL). ${ }^{1}$ Direct binding of $\mathrm{MM}$ cell to bone marrow cells and induced cytokines in turn regulates various signaling pathway like Ras/mitogen activated protein kinase (MAPK), Janus kinase (JAK)/Signal transducers and activators of transcription 3(STAT-3) pathway, Phosphatidylinositol-3 kinase (P13K)/AKT pathway and protein kinase-C (PKC) (Figure-1). IL-6 is among the most important proliferation and survival factors in myeloma. ${ }^{23}$ It transmits messages intracellularly through the signal transducing protein gp130, which can activate two pathways: the JAK-STAT pathway ${ }^{24}$ and the RasMAP kinase pathway. ${ }^{25}$ Through the former pathway, the ant apoptotic proteins $\mathrm{Mcl}-1^{24}$ and $\mathrm{Bcl}^{2} \mathrm{X}_{\mathrm{L}}{ }^{26}$ are upregulated; through the latter pathway, transcription factors, such as Elk-1, AP-1and NF-IL-6 ${ }^{24}$ are upregulated. Another pathway that is triggered by IL-6 via a protein called PK $\mathrm{C}-\delta$ are PI3K/Akt and MAPK. The overall effects of all these pathways are prevention of apoptosis, enhancement of multiple myeloma proliferation, drug resistance, and migration of MM cell in the bone marrow milieu. Targeting these signaling proteins may therefore be useful therapeutic strategies. ${ }^{27}$

Other cytokines like IL-1 $\beta$, up regulates production of IL6 , changes expression of cell adhesion molecules and has been shown to have osteoclast activating factor (OAF) activity. MM cells also secrete VEGF which may account for bone marrow angiogenesis, it also triggers increased growth and motility of $\mathrm{MM}$ cells in the bone marrow. ${ }^{28}$ Another potential angiogenic molecule in $\mathrm{MM}$ is fibroblast growth factor (FGF) which interact with FGF receptors (FGFRs) and it can directly trigger the neovascularization process by stimulating the migration and proliferation of human endothelial cells. Higher basic FGF levels have been found in more advanced stages of multiple myeloma. ${ }^{29}$ It is a potent angiogenic factor. IGF1 directly stimulates the growth of myeloma cell, enhances the myeloma cell responsiveness to IL-6 through $\mathrm{MAPK}^{30}$ and also inhibiting the apoptosis by increasing the expression of $\mathrm{Bad}^{31}$

\section{CLINICAL MANIFESTATIONS}

Multiple myeloma can cause wide range of nonspecific symptoms due to its damaging effect on the bone, the production of the abnormal paraproteins, and by interruption of normal production of blood cells. These signs and symptoms vary according to organ affected and these have been presented below: 


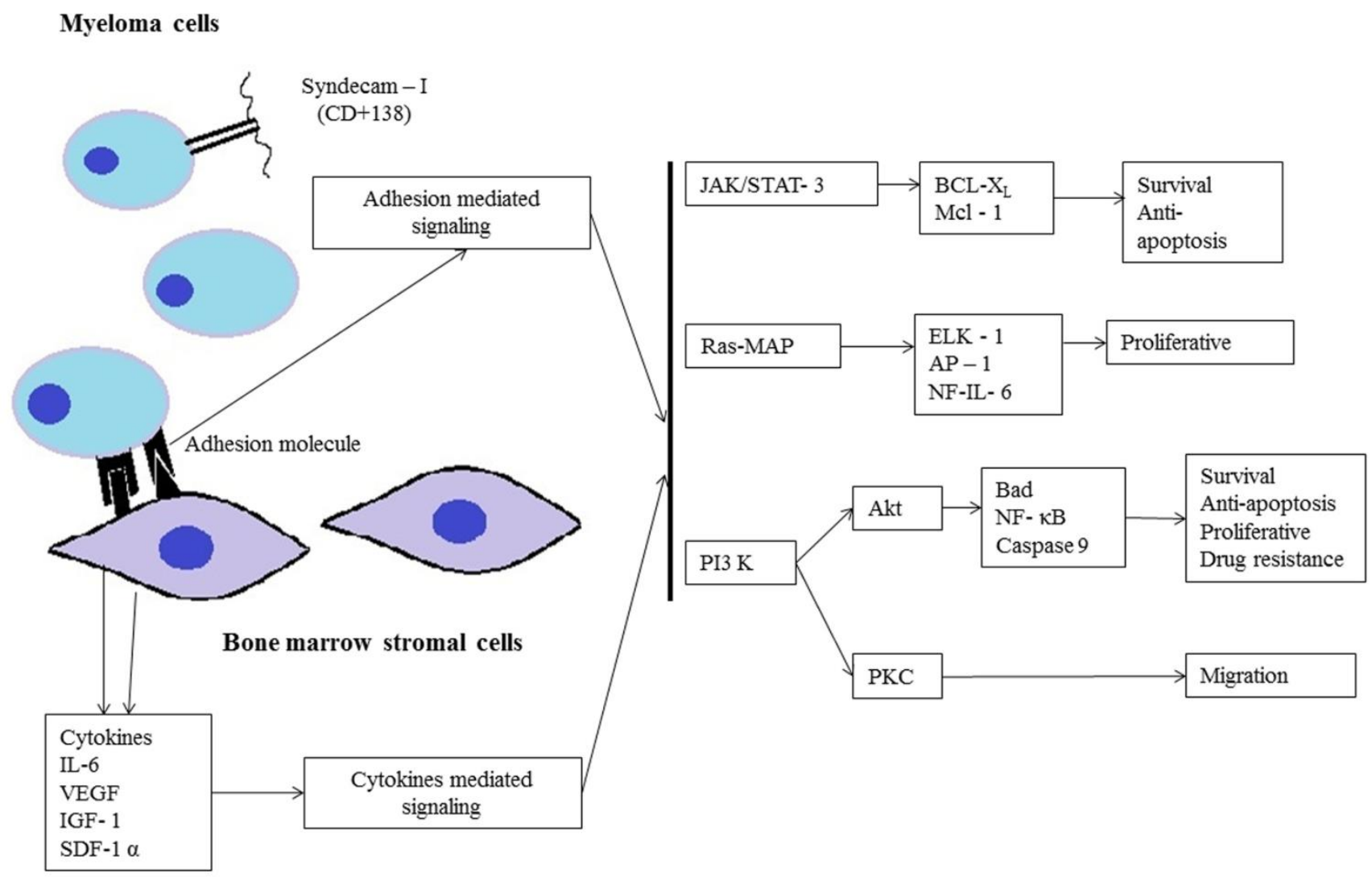

IL-6 = Interleukin- 6 , VEGF = Vascular endothelial growth factor, IGF-1 $=$ Insulin like growth factor, SDF- ${ }^{a}=$ Stromal derived factor $-1^{a}$, JAK/STAT-3 = Janus kinase/Signal transducer and activators of transcription-3, PI3K $=$ Phosphatidylinositol -3 kinase, PKC $=$ Protein kinase $\mathrm{C}, \mathrm{BCL}-\mathrm{X}_{\mathrm{L}}=\mathrm{B}$ cell lymphoma gene, $\mathrm{Mcl}-1=$ Myeloid cell leukemia $-1, \mathrm{ELK}-1=\mathrm{E}$ twenty six (ETS) like transcription factor, AP-1 $=$ Activator promotor $1, \mathrm{NF}=$ Nuclear factor, $\mathrm{Bad}=\mathrm{Bcl} 2$ associated death promotor.

Figure 1: Pathogenesis of multiple myeloma.

\section{Bone pain}

Bone pain is the most common symptom in myeloma, affecting nearly $70 \%$ of the patients and it usually involves the back and ribs. Persistent localized pain in a patient with myeloma usually signifies a pathologic fracture. Myeloma bone disease is due to the overexpression of RANKL by bone marrow stroma. RANKL activates osteoclasts, which resorb bone. The resultant bone lesions are lytic in nature which are best seen in plain radiographs, which may show "punchedout" resorptive lesions (including the "pepper pot" appearance of the skull on radiography). ${ }^{1}$

\section{Hypercalcemia}

Hypercalcemia occurs in $18-30 \%$ of patients. The symptoms of hypercalcemia include nausea, vomiting, tiredness, mental confusion, fatigue, constipation, abdominal pain, and weight loss. Raised calcium levels may impair kidney function. ${ }^{27}$

\section{Renal failure}

Renal failure occurs in nearly $25 \%$ of myeloma patients, and hypercalcemia is the most common cause of renal failure. Glomerular deposits of amyloid, hyperuricemia, recurrent infections and frequent use of nonsteroidal antiinflammatory agents (NSAIDs) for pain control, use of iodinated contrast dye for imaging, bisphosphonate use, and occasional infiltration of the kidney by myeloma cells all may contribute to renal dysfunction. It may also be due to tubular damage from excretion of light chains, also called Bence Jones proteins, which can manifest as the Fanconi syndrome (type II renal tubular acidosis). ${ }^{1}$

\section{Infection}

Many patients with myeloma develop infections with Gram-positive (e.g. Streptococcus pneumoniae, Staphylococcus aureus and Haemophilus influenzae) and Gram-negative (Pseudomonas aeruginosa) microorganisms. The greatest risk period for the occurrence of infection is in the initial few months after 
the start of chemotherapy. ${ }^{10,32,33}$.The most common infections are pneumonias and pyelonephritis. The increased risk of infection is due to immune deficiency resulting from diffuse hypogammaglobulinemia, abnormalities in complement functions, and therapeutic agents like dexamethasone. ${ }^{1}$

\section{Hyperviscosity}

Hyperviscosity refers to an increase in the viscosity or resistance to flow of the blood and is due to excessive production of proteins by the malignant plasma cells, specifically monoclonal (M) proteins that attach themselves to platelets and interfere with platelet function. Signs and symptoms of hyperviscosity are bleeding, bruising, headache, fatigue, sleepiness, neurologic symptoms, confusion, visual disturbances and retinopathy. ${ }^{1}$

\section{Anemia}

Anemia is the most common clinical feature of MM and it is usually normocytic, normochromic and related to the replacement of normal marrow by expanding tumor cells, inhibition of hematopoiesis by factors made by the tumor and also mild hemolysis. Patients may have megaloblastic anemia. ${ }^{27}$ Granulocytopenia and thrombocytopenia are very rare. Clotting abnormalities may be seen due to the failure of antibody-coated platelets to function properly or because of interaction of the $\mathrm{M}$ component with clotting factors I, II, V, VII, or VIII. $^{1}$

\section{Neurological symptoms}

Neurologic symptoms occur in $5-15 \%$ of patients, and there are many causes for it like hypercalcemia (causes produce lethargy, weakness, depression, and confusion), hyperviscosity (leads to headache, fatigue, visual disturbances, and retinopathy), bony damage and collapse, (leads to cord compression, radicular pain, and loss of bowel and bladder control) and infiltration of peripheral nerves by amyloid (can be a cause of carpal tunnel syndrome and other sensorimotor mono- and polyneuropathies). Sensory neuropathy is also a side effect of thalidomide and bortezomib therapy. Spinal cord compression is a medical emergency and requires immediate treatment to relieve the pressure and prevent permanent damage. ${ }^{1}$

\section{DIAGNOSIS}

The diagnosis of myeloma is established by the presence of bone marrow plasmacytosis $(>10 \%)$, serum and/or urine $\mathrm{M}$ component and end organ damage. Bone marrow plasma cell are CD138+ and monoclonal. Proliferation of MM is measured by the plasma cell labeling index (PCLI), $\beta_{2}$ microglobulin or gene expression profiling (GEP). GEP has been utilized to identify high risk patients and to differentiate between normal plasma cells, those in MGUS, MM and extramedullary plasmacytomas. ${ }^{34,35}$ The $M$ protein can be detected by serum protein electrophoresis in $82 \%$ of patients and by immunofixation in $93 \%{ }^{7}$ The serum $\mathrm{M}$ component will be $\operatorname{IgG}$ in $53 \%$ of patients, $\operatorname{IgA}$ in $25 \%$, and $\operatorname{IgD}$ in $1 \%$. Upto $20 \%$ of patients will have only light chains either kappa/lambda $(\kappa / \lambda)$ in serum and urine. ${ }^{1}$ Serum free light chain (FLC) ratio $\kappa / \lambda$ is useful in diagnosing and monitoring the course of the disease and response to therapy particularly in patients with light chain myeloma who do not have detectable $\mathrm{M}$ protein on serum or urine electrophoresis. ${ }^{36} \mathrm{FLC} \kappa / \lambda$ ratio (reference range 0.26 $1.65)$ is used to distinguish polyclonal elevations seen with renal dysfunction from monoclonal elevation. ${ }^{37}$

The International Myeloma Working Group (IMWG) has established a criteria 'CRAB' based on end organ damage to distinguish asymptomatic myeloma from active disease. These include $\mathrm{C}$ hypercalcemia, $\mathrm{R}$ renal insufficiency, A anemia and B bone lesion. ${ }^{38}$

The most important differential diagnosis in patients with myeloma involves their separation from individual with MGUS, SMM and primary amyloidosis. Patient with MGUS or SMM should be identified and not treated unless symptoms develop or laboratory abnormalities progress because they remain stable for many years. Patients with MGUS have M protein $<3 \mathrm{~g} / \mathrm{dl}$, absence of lytic bone lesions, anaemia, hypercalcemia and bone marrow with $<10 \%$ plasma cells. The patients with MGUS go on to develop multiple myeloma. For Patients with serum $\mathrm{M}$ protein $<1.5 \mathrm{~g} / \mathrm{dl}$, IgG subtype and normal serum FLC $\kappa / \lambda$ ratio the risk of conversion is low $(5 \%$ at 20years). Patients with serum $M$ protein $>1.5 \mathrm{~g} / \mathrm{dl}, \mathrm{IgA}$ subtype and abnormal serum FLC ratio have a higher risk for conversion to myeloma (58\% at 20years), and they should be followed up at 3-6 month interval. ${ }^{39} \mathrm{SMM}$ is characterized by the presence of a serum $\mathrm{M}$ protein $(\mathrm{IgG}$ or $\operatorname{IgA} \geq 3 \mathrm{~g} / \mathrm{dl}), \geq 10 \%$ of atypical plasma cells in the bone marrow and absence of target organ damage. The probability of progression to $\mathrm{MM}$ is $10 \%$ per year for the first 5 years, $3 \%$ per year for next 5 year and $1 \%$ for the next 10years. ${ }^{40}$

\section{PROGNOSIS}

Survival of patients with MM depends on disease stage. Although median survival is approximately 3 years, ${ }^{7}$ some patients with MM can live longer than 10 years. $^{41-43}$ Since 1975, the Durie-Salmon staging system has been used to stratify patients with MM. ${ }^{44}$ but it has limitations, especially in the categorization of bone lesions. ${ }^{45,46}$ Greipp et $\mathrm{al}^{47}$ have developed the new International Staging System (ISS), which overcomes the limitations of the Durie-Salmon staging and divides patients into 3 distinct stages solely on the basis of serum $\beta 2$ microglobulin and albumin levels. The ISS is the most widely used method of assessing prognosis (Table-1). Cytogenetic analysis of myeloma cells may be of prognostic value, the deletion of chromosome 13, translocations of $\mathrm{t}(4 ; 14), \mathrm{t}(14 ; 16) \mathrm{t}(14 ; 20)$ confers poorer prognosis. By contrast a favourable prognosis has been observed in the presence of $\mathrm{t}(11 ; 14), \mathrm{t}(6 ; 14)$ or 
hyperdiploidy. ${ }^{17,48,49}$ Syndecan -1 (also known as CD138) is found on the surface of almost all myeloma cells, whether they are in the bone marrow or the blood. The myeloma cell can use it to attach itself to the other cell. Syndecan-1 can be shed into the serum by the action of enzymes called proteases, means it accumulates in the serum of myeloma patients. High level of syndecan -1 in the serum correlates with the poor prognosis. ${ }^{22}$

Table 1: International Staging System (ISS) for Multiple Myeloma. ${ }^{47}$

\begin{tabular}{|ll|l|}
\hline & Level & $\begin{array}{l}\text { Median } \\
\text { Survival } \\
\text { (Months) }\end{array}$ \\
\hline Stage 1 & $\begin{array}{l}\text { Serum } \beta 2 \text {-microglobulin }<3.5 \\
\mu \mathrm{g} / \mathrm{mL} .\end{array}$ & 62 \\
& Serum albumin $\geq 3.5 \mathrm{~g} / \mathrm{dL}$ & \\
\hline \multirow{2}{*}{ Stage II } & $\begin{array}{l}\text { Serum } \beta 2 \text {-microglobulin= 3.5- } \\
\text { S.5 } \mu \mathrm{g} / \mathrm{mL} .\end{array}$ & 44 \\
& Serum albumin $\leq 3.5 \mathrm{~g} / \mathrm{dL}$ \\
\hline Stage III & $\begin{array}{l}\text { Serum } \beta 2 \text {-microglobulin }>3.5 \\
\mu \mathrm{g} / \mathrm{mL} .\end{array}$ & 29 \\
\hline
\end{tabular}

\section{TREATMENT}

Patients with symptomatic and/or progressive myeloma require therapeutic intervention. Therapy can significantly prolong survival and improve the quality of life of myeloma patients. Patients with inactive or SMM should be closely monitored without instituting therapy, as no survival benefit/ advantage has been demonstrated by treating asymptomatic multiple myeloma. ${ }^{50,51} \mathrm{~A}$ long term plan for managing the disease should be formulated before instituting therapy for symptomatic disease (Figure 2). In general MM therapy includes symptomatic supportive care \& systemic therapy. Symptomatic supportive care to prevent serious morbidity from the complications of the disease which includes adequate hydration, bisphosphonates, management of renal failure, anemia and infection. Systemic therapy is to control the progression of myeloma and is tailored to patients' age, comorbidities and preferences. Patients who are $<65$ years of age with no major co-morbid conditions are usually eligible for high dose therapy and autologous stem cell transplantation (HDT\&ASCT) whereas patient with $>65$ years of age with cardiac or renal disease are not eligible for HDT \& ASCT. Local treatments, such as radiation therapy is often given to patient with $\mathrm{MM}$ in order to control or kill the cancer cell in a certain area.

\section{Treatment of myeloma in patients eligible for transplantation}

Treatment of the young patient population, aged $<65$ years or older if in good performance status, should be based on HDT/ASCT. After initial induction therapy, stem cells are collected to perform HDT/ASCT. Subsequent consolidation and maintenance strategies are recommended.

\section{Induction therapy}

The aim of induction therapy is maximal disease control to collect tumour-free peripheral blood stem cells (PBSCs). Typically patients are treated with approximately four cycles of induction therapy before stem cell harvest. This includes patients who are transplantation candidates but who wish to reserve ASCT as a delayed option for relapsed/refractory disease. Such patients can resume induction therapy following stem cell collection until a plateau phase is reached; reserving ASCT for relapse.The sensitivity to the initial induction therapy is measured by the M-protein which is the most important predictor of complete response (CR). Earlier vincristine, doxorubicin, dexamethasone (VAD) was used as pre-transplant induction therapy. However, VAD has drawbacks such as requiring an intravenous indwelling catheter and neurotoxicity from vincristine. The other induction regimen used was cyclophosphamide, idarubicin and dexamethasone. With the use of these conventional chemotherapy regimens the post-transplant $\mathrm{CR}$ rate has been about $35 \%$ and the median overall survival (OS) of six years in the best circumstances. ${ }^{52}$ Induction therapy with melphalan-based regimen should be avoided as it can interfere with adequate stem cell mobilization. ${ }^{53}$ The current availability of new drugs such as thalidomide, lenalidomide and bortezomib have provided the framework for improving the results of ASCT.

At present, a combination of immunomodulators (thalidomide or lenalidomide and dexamethasone) or proteasome inhibitors (bortezomib and dexamethasone) are used for induction. The overall response rate (ORR) with these combinations are superior to four day continuous infusion of vincristine, adriamycin and oral dexamethasone (VAD). ${ }^{54}$ Thalidomide emerged as the first important new drug treatment for myeloma following recognition of its anti-angiogenic effects in the 1990s. Thalidomide is given orally and has immunomodulatory anti-inflammatory and apoptotic effects. Thalidomide/dexamethasone (Thal/Dex) was approved by the US Food and Drug Administration (FDA) in $2006^{55}$ for use as pre-transplant induction regimen. The use of Thal/Dex in newly diagnosed myeloma was initially based on three phase II clinical trials. $^{56,57}$ A case-control study of 200 patients demonstrated that response rates with VAD were significantly lower compared to Thal/Dex combination $(76 \% \mathrm{v} / \mathrm{s} 52 \%) .{ }^{58}$ Preliminary results from other randomized trials confirm these findings. ${ }^{59,60}$ The Eastern Cooperative Oncology Group (ECOG) in 2006 compared Thal/Dex to dexamethasone alone in 207 patients. ${ }^{61}$ The best response within four cycles of therapy was significantly higher with Thal/Dex as compared to dexamethasone alone (63\% versus $41 \%$ ). Dexamethasone alone has also been used as induction therapy, with an objective response rates of approximately $45 \%,{ }^{61}$ which is significantly lower as compared to newer induction regimen and the early mortality rate (first 4 months of therapy) associated with dexamethasone is over $10 \%$, 
reflecting the toxicity and ineffectiveness of this regimen. Consequently, single-agent dexamethasone is no longer recommended as initial therapy. ${ }^{62}$ Thalidomide combined with dexamethasone is an effective pre-transplantation induction regimen. ${ }^{63}$ The most frequent adverse effects seen with thalidomide based regimens were somnolence, constipation, neuropathy and fatigue. The less common ones were edema, venous thrombosis, skin rash, bradycardia, neutropenia and hypothyroidism. Thalidomide is a teratogenic drug and is contraindicated in pregnancy. In elderly patients the use of thalidomide may cause disturbing constipation and neuropathy. ${ }^{64}$

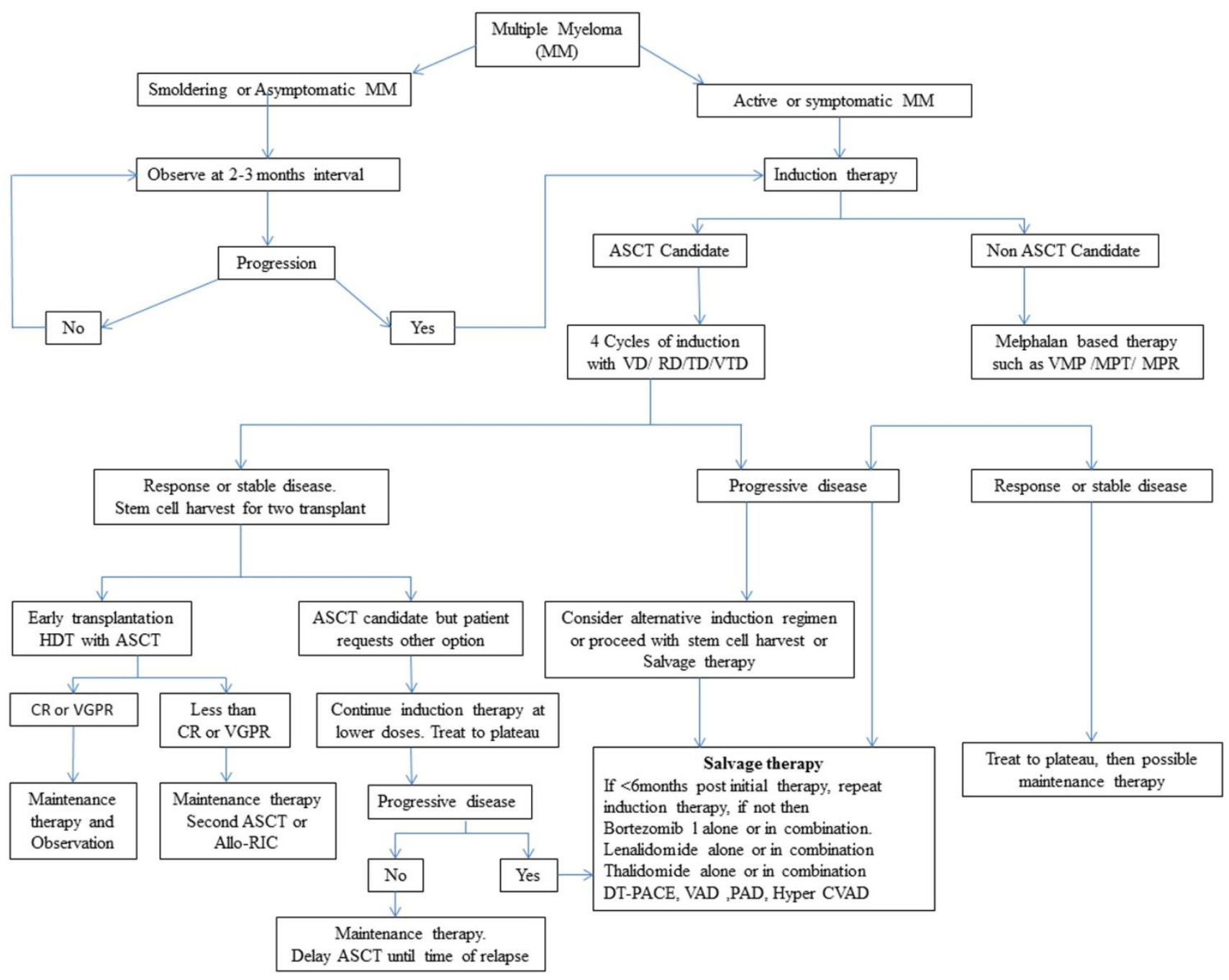

ASCT $=$ Autologous stem cell transplantation, Allo-RIC $=$ Dose reduce intensity conditioning allogenic transplantation, MP $=$ Melphalan Prednisolone. V $=$ Velcade/Bortezomib, $\mathrm{R}=$ Revelimid/Lenalidomide. $\mathrm{T}=$ Thalidomide, $\mathrm{D}=$ Dexamethasone, DT $\mathrm{PACE}=\mathrm{Dexamethasone}$, Thalidomide, Cisplatin, Doxorubicin, cyclophosphomide, Etopside. VAD = Vincritine, Doxorubicin, Dexamethasone. PAD = Bortezomib, Doxorubicin, Dexamethasone. Hyper CVAD =

Cyclophosphomide, Doxorubicin, Vincristine, Dexamethasone. HDT = High dose chemotherapy, CR = Complete response, VGPR = Very good partial response

Figure 2: Approach to the treatment of multiple myeloma.

Lenalidomide (Revlimid) is an oral thalidomide analogue and acts by similar mechanisms, targeting both signalling pathways within the malignant plasma cell and the bone marrow microenvironment. Lenalidomide is frequently effective even in patients whose myeloma is resistant to thalidomide. A phase II trial conducted at the Mayo Clinic demonstrated remarkably higher activity (91\% response rate) with the Len/Dex regimen in newly diagnosed myeloma. ${ }^{65}$ ECOG tested Rev/Dex (40mg/day for 4days per week) versus Rev/low-dose Dex (40 mg dexamethasone once weekly) ${ }^{66}$ which showed that toxicity rates are significantly higher with Rev/high-dose Dex compared to Rev/low-dose Dex. The early mortality rate (first 4 months) in the Rev/low-dose dexamethasone was probably the lowest mortality $(0.5 \%)$ reported in any large phase III newly diagnosed myeloma trial therefore making it one of the safest pre-transplant induction regimens for myeloma. A combination of lenalidomide 
and low dose dexamethasone (40 mg once a week) is the standard schedule, ${ }^{67}$ and approved by FDA in June $2006 .{ }^{68}$ Lenalidomide is free of somnolence, but causes mild constipation, minimal neuropathy, neutropenia, thrombocytopenia and thromboembolism therefore, requiring close monitoring. Effective contraception is also required because of its teratogenic potential and it require dose modification in patients with renal failure. ${ }^{64}$ There has been some concern about collection of progenitor cells after lenalidomide therapy ${ }^{69}$ but this appears to be minimized if a combination of cyclophosphamide and a growth factor is used for mobilization. ${ }^{70}$ More recently, a new chemokine receptor inhibitor plerixafor has been studied for its effects on stem cell mobilization. Plerixafor in combination with GCSF has been successfully used in patients failing previous mobilization attempts. It overcomes the negative effects of lenalidomide on stem cell mobilization. ${ }^{71-}$

${ }^{74}$ These results led to the FDA and European Medicines Agency (EMA) approval of plerixafor in combination with G-CSF in 2008 and 2009, respectively, in patients with non-Hodgkin lymphoma and $\mathrm{MM}^{75}$ At present, stem cell collection is usually done after 4 cycles of lenalidomide and dexamethasone. ${ }^{76}$ Patients receiving thalidomide or lenalidomide in combination with highdose steroids need routine thromboprophylaxis with coumarin or low-molecular weight heparin (LMWH). Aspirin can be used instead in patients receiving only low doses of dexamethasone (40 mg, 4 days a month or lower) or prednisone in combination with thalidomide, provided no concomitant erythropoietic agents are used. ${ }^{62}$

Another regimen with high anti-myeloma activity is the association of bortezomib (Velcade) and dexamethasone. ${ }^{77,78}$ Bortezomib is a potent, reversible, and selective inhibitor of the $26 \mathrm{~S}$ proteasome targets the myeloma cell and the bone marrow microenvironment and acts by inhibiting the binding of myeloma cells to stromal cells and decrease bone marrow triggered angiogenesis. ${ }^{79}$ In newly diagnosed myeloma, bortezomib has shown response rates of approximately $40 \%$ as a single-agent, ${ }^{80} 70-90 \%$ in combination with dexamethasone (Vel/Dex), ${ }^{77,81}$ or with thalidomide and dexamethasone (VTD). A combination of bortezomib with dexamethasone, doxorubicin, lenalidomide or thalidomide and melphalan has synergistic activity and may overcome resistance to either agent. ${ }^{82-85}$ Harousseau and colleagues reported superior response rates and longterm outcome with Vel/Dex compared to VAD. ${ }^{86}$

The main drawback of bortezomib-based therapy is the need for intravenous therapy. No adverse effect on stem cell mobilization has been noted. No increased risk of deep vein thrombosis (DVT) was observed with bortezomib- based regimen $(<5 \%)$. The most common adverse events seen were sensory neuropathy $(31 \%)$, constipation $(28 \%)$, myalgia $(28 \%)$ and fatigue $(25 \%)^{81}$ and higher frequency of herpes zoster infection. ${ }^{87}$ For patients with neuropathy, the dose of bortezomib can be reduced to $1 \mathrm{mg} / \mathrm{m}^{2}$ or even $0.7 \mathrm{mg} / \mathrm{m}^{2}$. However, the benefit of bortezomib-based combinations is in elderly patients with impaired renal functions (creatinine clearance $<60 \mathrm{ml} / \mathrm{minute}$ ), and those with high risk cytogenetics including the presence of $\mathrm{t}(4 ; 14), \mathrm{t}(14 ; 16)$ translocation or a $17 \mathrm{p}$ deletion. ${ }^{80}$

Thus, treatment with thalidomide, lenalidomide or bortezomib in combination with dexamethasone is associated with higher response rates than conventional therapy. It is not clear which of these combinations is better. The toxicity profile, cost analysis, quality of life and long term follow up data will help to choose one combination over the other. ${ }^{88}$ The real impact of increased $\mathrm{CR}$ rates, when incorporating novel agents in the pre-transplant induction regimens, on the long-term post-ASCT outcome require more prolonged follow-up.

\section{High dose chemotherapy (HDT) with Autologous Transplantation (ASCT)}

High-dose chemotherapy followed by ASCT is considered the gold standard in the initial therapy of younger patients with MM. The stem cell must be collected using granulocyte-colony stimulating factor (GCSF), with or without cyclophosphamide before the patient is exposed to conditioning therapy. The backbone of conditioning therapy is melphalan, administered at doses ranging from 100 to $200 \mathrm{mg} / \mathrm{m}^{2}$, dependent on age and preexisting comorbidities. ${ }^{89}$ During the past decade, a number of randomized and nonrandomized studies have shown that treatment with high dose melphalan therapy (HDT) $(200 \mathrm{mg} / \mathrm{m} 2)$ followed by ASCT is associated with CR rates of $40 \%-50 \%$ with improved OS and eventfree survival (EFS). ${ }^{90-92}$ ASCT prolongs survival in MM, but its timing (early vs delayed) is controversial. Three randomized trials showed that survival is similar whether ASCT is done early (immediately after 4 cycles of induction therapy) or delayed (at the time of relapse as salvage therapy). ${ }^{93,94}$ In a randomized trial of the Spanish Programa para el Estudio de la Terapéutica en Hemopatía Maligna (PETHEMA) group, patients responding to induction therapy had similar OS and PFS with either ASCT or 8 additional courses of chemotherapy, ${ }^{92}$ suggesting that the greatest benefit from ASCT may be in those with disease refractory to induction therapy. ${ }^{95,96}$ Overall, given the inconvenience, adverse effects of prolonged chemotherapy, cost and other issues, early ASCT is still favorable, especially for patients younger than 65 years with adequate renal function. ${ }^{97}$ However, with effective new agents to treat MM, some patients and physicians may choose to delay the procedure. The need for early ASCT is an important question for future clinical trials.

A second ASCT is recommended by the NCCN Guidelines within 6 months of the initial ASCT for those patients who did not achieve at least a very good partial remission (VGPR) after the first ASCT ${ }^{89}$ Various studies reported that two successive HDTs (Double or Tandem ASCT) are more effective than single HDT in the subset of patients who do not achieve a CRs or (VGPR) to the 
first transplant. ${ }^{98,99}$ Kumar et al have recently reported the result of a metaanalysis of six randomized trials where the response rate was significantly better with double transplant, whereas the mortality rate was higher with no improvement in OS for patients treated with tandem transplant. ${ }^{100}$ The two major shortcomings of ASCT are that myeloma is not eradicated even with the large doses of chemotherapy and that autologous peripheral stem cells are contaminated by myeloma cells or their precursors (Graft versus myeloma effect GVM), so this procedure is not curative and most patients relapse.

Allogeneic stem cell transplantation remains the only potential curative treatment for $\mathrm{MM}$ patients. The advantage of allogeneic transplantation are the lack of graft contamination with tumor cells and the presence of GVM effect. ${ }^{101,102}$ However only $5-10 \%$ of patients are candidate for conventional allogeneic transplantation due to high transplant related mortality (TRM) from severe graft versus host disease (GVHD), availability of HLAidentical sibling donor in only one third of patients and age of the patients. Because of its high transplant-related mortality (TRM) the myeloablative allogeneic transplantation with conventional conditioning has been almost universally replaced by the so called dose reduced intensity conditioning allergenic transplantation (AlloRIC/ Miniallogeneic transplantation). During the past decade, a number of studies have explored the role of Allo-RIC from an HLA-identical sibling donor after debulking with ASCT but results are still controversial. $^{103-107}$ At this time, miniallogeneic transplantation is investigational. It should be considered only in the context of clinical trials in standard-risk MM.

\section{Treatment of myeloma in patients not eligible for transplantation}

In patients not eligible for ASCT the conventional therapy has consisted of intermittent pulses of an alkylating agent, melphalan and prednisone (MP) administered for 4-7 days every 4-6 weeks. With these regimens the ORR has been between $40-50 \%$ and the CR rate less than $5 \%$ with median survivals of about three years. The addition of novel agents thalidomide, bortezomib and lenalidomide with either MP or dexamethasone have shown improved results. Various trials comparing MPT (melphalan-prednisonethalidomide) with MP have showed that a combination of MPT is superior to MP in elderly patients in terms of CR, OS and EFS. ${ }^{108-111}$ MPT was associated with a higher risk of neurological adverse events (10\% vs $1 \%)$, infections $(10 \%$ vs $2 \%)$, cardiac toxicity $(7 \%$ vs $4 \%)$ and thromboembolism (12\% vs $2 \%$ ) as compared to MP regimen. ${ }^{109}$ Antithrombotic prophylaxis with LMWH, warfarin, or daily aspirin is recommended when using MPT. ${ }^{112}$ A study compared the association of Thal/Dexa with MP, Thal/Dexa produced a significantly higher ORR (68\% vs. $50 \%)$ but was more toxic in elderly patients thus resulting in a significantly shorter OS (41.5 vs. 49.4 months). ${ }^{113}$
In a phase I/II trial, safety and efficacy of MP in combination with lenalidomide (MPR) in newly diagnosed elderly myeloma patients were studied. ${ }^{114}$ At the maximum tolerated dose (lenalidomide $10 \mathrm{mg}$ plus melphalan $0.18 \mathrm{mg} / \mathrm{kg}$ ), partial response (PR) was $85 \%$. One year EFS and OS were $92 \%$ and $100 \%$ respectively. EFS of patients with deletion of chromosome 13 or chromosomal translocation $(4 ; 14)$ were not significantly different from those who did not have shown such abnormalities. By contrast, patients with high-levels of serum $\beta 2$-microglobulin experienced shorter EFS in comparison with those with low-levels of $\beta 2$ microglobulin. Adverse events were mainly related to hematological toxicities (neutropenia 66\%) whereas nonhematological side effects were less frequent and were febrile neutropenia (8\%), cutaneous rash $(10 \%)$ and thromboembolism $(6 \%)$. Rate of thrombotic complication was low with daily low dose aspirin prophylaxis.

An ECOG compared lenalidomide/dexamethasone at full
doses of dexamethasone rsus lenalidomide/dexamethasone at a dose of dexamethasone of $40 \mathrm{mg}$ weekly. The OS at one year was significantly longer with lenalidomide/low-dose dexamethasone due to a significantly lower toxicity. This difference was higher in patients older than 65 years. ${ }^{67}$

The combination of MP with bortezomib (MPV) was superior to MP in overall response rate (71\% vs. $36 \%)$, CR rate (30\% vs. 4\%), EFS (median, 24 vs. 16 months) and OS (82\% vs. $69 \%$ at two years). ${ }^{80}$ Importantly, MPV was superior to MP in all prognostic subgroups, including high-risk cytogenetics such as $\mathrm{t}(4 ; 14), \mathrm{t}(14 ; 16)$ and $17 \mathrm{p}$ deletion. Sensory neuropathy could be an important limitation of bortezomib in these elderly patients. ${ }^{79,115}$ Once the maximum response is achieved (after 6-9 cycles of MPT or MPR or 4-6 cycles of MPV patients can be kept on observation.

It seems that the association of MP or dexamethasone with a novel agent such as thalidomide, bortezomib or lenalidomide will become the standard of care for elderly patients with MM. The first choice will depend on the patient age and clinical status as well as on the disease characteristics.

\footnotetext{
Maintenance therapy

The concept of maintenance therapy may open new avenues for new treatment approaches in myeloma. Several trials have explored the benefits of maintenance strategies after ASCT or after induction therapy in transplant-ineligible patients in terms of response rate and survival. Maintenance therapy aims to prolong remission in long-term tumor control and to reduce the risk of relapse. ${ }^{116}$ Maintenance therapy with interferon alfa-2 is of limited value and is seldom used. ${ }^{117} \mathrm{~A}$ study by Berenson et al suggests that prednisone may be useful for maintenance therapy. With $50 \mathrm{mg}$ vs $10 \mathrm{mg}$ of prednisone taken orally every other day, PFS (14 vs 5 months) and overall survival (37 vs 26 months) were significantly
} 
longer. But the side-effects of long term steroid therapy preclude its routine use. ${ }^{118}$ The incorporation of new drugs as maintenance therapy appears to produce better results. The results of 3 randomized studies using thalidomide showed improved EFS. ${ }^{119-121}$ The OS was better in two studies ${ }^{119,120}$ but neuropathy (7-27\%) led to discontinuation of thalidomide in a proportion of patients. Lenalidomide may overcome this problem due to better tolerability. $^{122}$ Compared to placebo, lenalidomide maintenance significantly delays the time to progression (TTP). Specifically, McCarthy and colleagues ${ }^{123}$ showed an estimated median TTP of 42.3 months for the lenalidomide arm versus a TTP of 21.8 months for the placebo arm at 17.5 months from ASCT. Similarly, Attal and associates ${ }^{124}$ observed a median PFS from diagnosis of 52 versus 34 months in lenalidomide versus placebomaintained patients. Advantages in terms of PFS by lenalidomide maintenance have also been demonstrated by Palumbo and colleagues ${ }^{125}$ in the nontransplant setting. Bortezomib also showed promising results as a maintenance therapy, suggesting that bortezomib maintenance may favorably impact time to recurrence. ${ }^{126}$ Additional studies are needed to determine the role of routine maintenance in myeloma, especially the use of lenalidomide, which has a better safety profile than thalidomide for long-term maintenance.
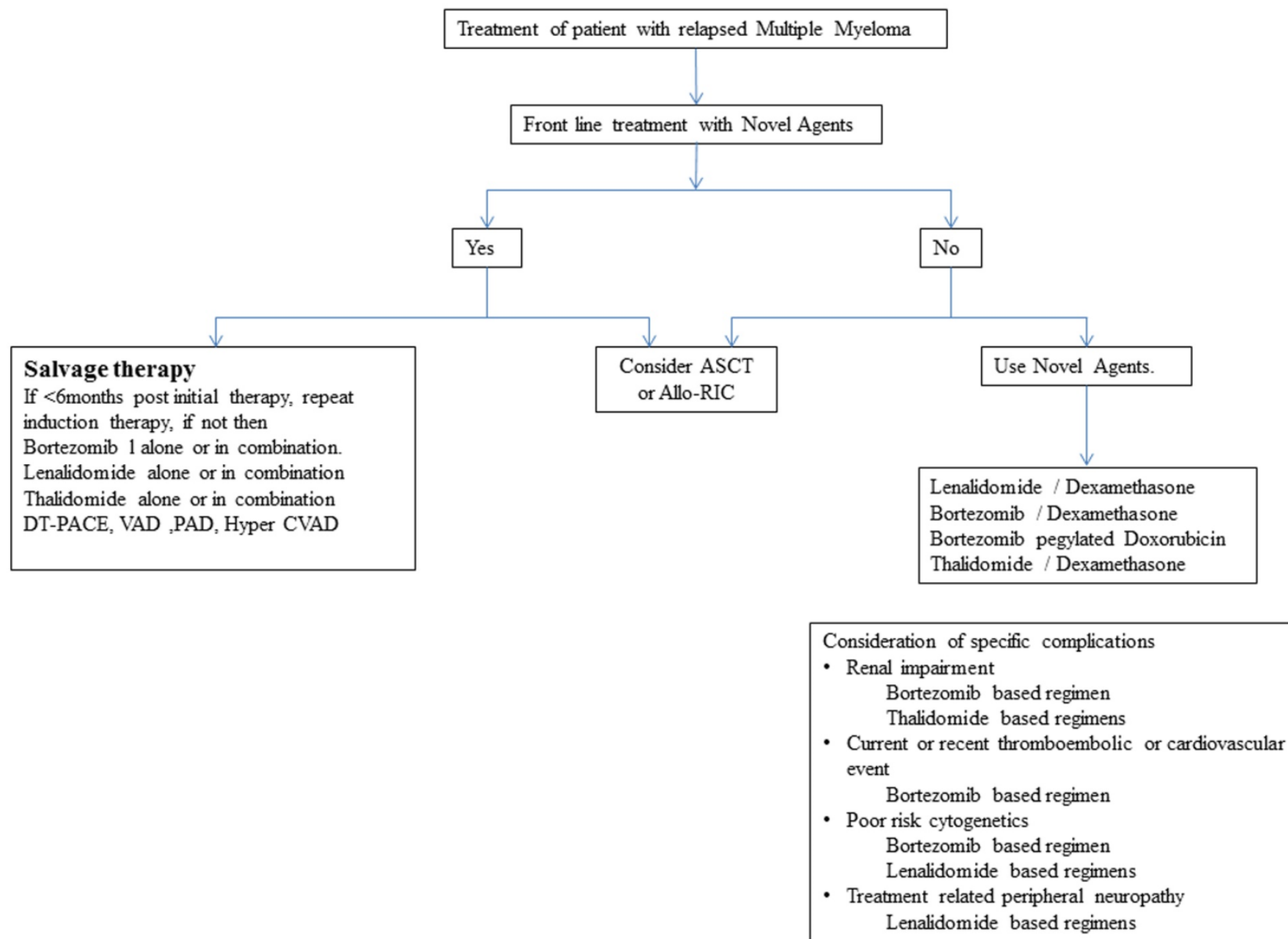

Figure 3: Treatment of relapsed multiple myeloma.

\section{Treatment of patients with relapsed /refractory disease}

Multiple myeloma relapses eventually in almost all patients and the treatment of patients with relapsed/refractory disease constitutes a real challenge. Treatment choices depend on previous therapies, duration of response and toxicities, age at the time of relapse, type of relapse (aggressive/indolent) and presence of highrisk cytogenetic features. ${ }^{127}$ Thalidomide-dexamethasone
(Thal/dexa), lenalidomide-dexamethasone (Len/dexa) and bortezomib-dexamethasone (Velc/Dexa) based combinations can be used for patients who relapse after MP/VAD chemotherapy (Figure 3). ${ }^{128,129}$ If relapse occurs more than 6 months after therapy ended, the initial chemotherapy regimen should be reinstituted. If relapse occurs after a shorter period of time from induction, treatment options include HDT/ASCT (Patients for whom 
stem cells were cryopreserved early in the disease) or Allo-RIC (young patients with preferably HLA-matched donors) or switch to a new regimen. ${ }^{130-133}$

Strategies approved in the relapsed setting include bortezomib alone or in combination with pegylated liposomal doxorubicin, and lenalidomide in combination with dexamethasone. ${ }^{129,134}$ A combination of bortezomib with pegylated liposomal doxorubicin (PLD) is superior to bortezomib alone in VGPR plus CR (27 vs. 19\%), TTP (median, 9.3 vs. 6.5 months) and OS at 15 months (76\% vs. $65 \%) .{ }^{134}$ Similarly the combination of lenalidomide plus dexamethasone was superior to dexamethasone alone in ORR (60\% vs. $22 \%)$, CR rate (15\% vs. $2 \%)$, median time to progression (TTP) (median 11 vs. 5 months) and OS (median, 29.6 vs. 20 months). ${ }^{135,136}$ Lenalidomide is active in thalidomide or bortezomibpretreated patients. Bortezomib alone or in combination with dexamethasone is active in thalidomide / lenalidomide pretreated patients. Bortezomib administered as a single agent induces an ORR and a CR rate up to $43 \%$ and $9 \%$ respectively. ${ }^{78,137}$

Ongoing studies are evaluating double, triple, and quadruple combinations, as well as additional targeted novel agents. Thalidomide has been combined with a variety of agents, such as dexamethasone, cisplatin, cyclophosphamide, and etoposide (DT-PACE) ${ }^{138}$ Safety and efficacy of lenalidomide plus pegylated liposomal doxorubicin or cyclophosphamide and dexamethasone have been additionally evaluated. ${ }^{139,140}$ Among the novel agents currently tested in myeloma, are the new immunomodulatory drug pomalidomide and proteasome inhibitorv carfilzomib are the most promising. Notably, activity of pomalidomide was also observed in patients refractory to thalidomide, lenalidomide, or bortezomib. ${ }^{141,142}$ In the relapsed/refractory setting, an overall response of $30 \%$ was achieved by drug pomalidomide, alone or in combination with dexamethasone. The dose-limiting adverse effect was myelosuppression. ${ }^{143,144}$ Carfilzomib in contrast to bortezomib, has an irreversible mechanism of action. ${ }^{145,146}$ Although high response rates were demonstrated in patients previously treated with lenalidomide, bortezomib, and HDT/ASCT, even higher response rates were observed in bortezomib-naïve patients. ${ }^{147}$ Reported toxicity was mainly hematologic A larger randomized phase III trial is planned to assess the combination of carfilzomib plus lenalidomide plus dexamethasone in the setting of relapsed disease.

\section{SUPPORTIVE THERAPY}

Supportive care is as important as the treatment of primary tumor. Supportive therapies in MM aim to prevent and treat bone disease and its complications, thromboembolic events, renal impairment, hyperviscosity, infections, and anemia (Table 2). It is symptomatic and as discussed below:
Table 2: Supportive therapies in Multiple Myeloma.

\begin{tabular}{|ll|}
\hline Bone disease & $\begin{array}{l}\text { Bisphosphonates. } \\
\text { Kyphoplasty, Vertebroplasty. } \\
\text { Radiation. }\end{array}$ \\
\hline Anaemia & Erythropoietin \\
\hline Hypercalcemia & $\begin{array}{l}\text { Hydration and Bisphosphonates, } \\
\text { eventually calcitonin. }\end{array}$ \\
\hline Infections & Immunoglobulin. \\
\hline $\begin{array}{l}\text { Thromboembolic } \\
\text { events }\end{array}$ & $\begin{array}{l}\text { Anticoagulation strategies in } \\
\text { case of thalidomide or } \\
\text { lenalidomide-based regimens. }\end{array}$ \\
\hline Renal failure & $\begin{array}{l}\text { Hydration. } \\
\text { Avoid NSAIDs and nephrotoxic } \\
\text { drugs. }\end{array}$ \\
\hline
\end{tabular}

\section{Bone Lesion}

Patients with symptomatic bone disease or asymptomatic patients whose bone imaging suggests decreased bone density benefit from therapy with bisphosphonates. ${ }^{148}$ Indeed, monthly infusions with zoledronate or pamidronate reduce skeletal complications (hypercalcemia, fractures, and pain). Zoledronic acid may be superior to pamidronate. ${ }^{149,150}$ Treatment can be continued (once in 6 months) in patients with persistent bone disease or osteoporosis and should be resumed in case of disease progression or relapse. Patients with persistent localized bone pain can get benefit from vertebroplasty and kyphoplasty. ${ }^{151}$

\section{Anaemia}

The various causes of anaemia in myeloma are inadequate levels of erythropoietin (present in up to $50 \%$ ), iron, folate and vitamin $\mathrm{B}_{12}$ deficiency. ${ }^{152}$ Following response to antimyeloma therapy, anaemia responds in most patients. Randomized placebocontrolled trials have shown that symptomatic anemia often is improved by administration of erythropoietin. ${ }^{153,154}$ Erythropoietin $(40,000 \quad \mathrm{U}$ subcutaneously, weekly) or darbepoetin (200 $\mu \mathrm{g}$ subcutaneously every 2 weeks) is beneficial. Blood transfusions are indicated for patients with symptomatic anemia who do not benefit from other therapies.

\section{Infections}

Prophylaxis against Pneumocystis carinii pneumonia should be considered in all patients receiving high-dose corticosteroidal therapy. A small randomized placebocontrolled trial of trimethoprim-sulfamethoxazole in 57 patients with newly diagnosed MM showed benefit with routine prophylaxis administered with the first 2 cycles of chemotherapy. ${ }^{155}$ Alternative agents such as ciprofloxacin, levofloxacin, or cephalosporins for $P$ carinii pneumonia prophylaxis should be considered. Intravenous gamma globulin given every 3 to 4 weeks is indicated if patients have recurrent serious infections associated with severe hypogammaglobulinemia. Intravenous immunoglobulin may be considered as an 
adjuvant in patients with serious infections. ${ }^{33,107,156}$ Nephrotoxic antibiotics, like aminoglycosides should be avoided in patients with compromised renal functions. ${ }^{10,64}$

\section{Renal failure}

The main causes of renal failure in MM are cast nephropathy (80\%), light chain deposition (5\%-6\%) and amyloidosis $(<10 \%)$. Other factors like dehydration, hypercalcaemia, hyperuricaemia, infections and nephrotoxic drugs (e.g. aminoglycosides and NSAIDs) are reversible and should be corrected ${ }^{4}$ and avoided. ${ }^{157,158}$ Maintenance of a high urinary output $(3 \mathrm{~L} / \mathrm{d})$ is important in preventing renal failure in those with high levels of monoclonal light chains in the urine. Dexamethasone or bortezomib alone, or bortezomib with dexamethasone with/ without doxorubicin, or thalidomide with dexamethasone or VAD are preferred in patients with renal failure. Plasmapheresis should be considered in such patients in an attempt to prevent irreversible renal damage. ${ }^{159}$

\section{Deep Vein Thrombosis (DVT)}

Patients undergoing thalidomide- and lenalidomide-based therapies are at high risk for thromboembolic events and benefit from the regular use of anticoagulants. Based on risk-stratification analysis, aspirin, low-molecular-weight heparin, or warfarin may be administered. The duration of prophylaxis is 4-6 months. ${ }^{64,160}$

\section{Hyperviscosity Syndrome}

Infrequently, patients with MM develop hyperviscosity syndrome. Plasmapheresis promptly relieves the symptoms and should be performed if the patient has signs or symptoms of hyperviscosity. ${ }^{161}$

\section{NEW THERAPIES / FUTURE PERSPECTIVES/ NEW INVESTIGATIONAL AGENTS}

Despite the development of more effective therapies for multiple myeloma (MM) over the past decade, nearly all patients will eventually experience progressive disease or disease relapse and require further therapy. Designing the next generation of therapies for relapsed and refractory disease will depend on understanding the complex molecular pathogenesis of $\mathrm{MM}$ and mechanisms of resistance. Direct interaction between MM cells and bone marrow cells activates pleiotropic signaling pathways that mediate growth, survival, and migration of MM cells as well as resistance to chemotherapy. The bone marrow also secretes growth factors and cytokines that maintain MM cells and inhibit apoptosis. Therefore, successful therapeutic strategies must target not only the MM plasma cell but also the bone microenvironment. The benefit of immunomodulatory drugs such as thalidomide and lenalidomide and the proteasome inhibitor bortezomib in relapsed/refractory MM is related to their ability to target both. Novel agents and combination strategies are building on the success of these agents and targeting synergistic pathways. Among that, the most promising are the immunomodulatory drug pomalidomide, which can be active even in patients refractory to lenalidomide, the proteasome inhibitor carfilzomib, active in patients resistant to bortezomib and with an acceptable safety profile, and the histone deacetylase inhibitors (HDAC), particularly vorinostat (SAHA) and panobinostrat (LBH 589). ${ }^{162,163}$ Carfilzomib is approved by FDA on July $2012^{164}$ for the treatment of patients with MM who have received at least two prior therapies, including bortezomib and an immunomodulatory agent and have demonstrated disease progression on or within 60 days of the completion of the last therapy. Pomalidomide has shown promise in phase II trials and a new drug application for it has been submitted to the FDA. ${ }^{165}$

Histone deacetylase inhibitors, particularly vorinostat and panobinostrat act by increasing the productions of proteins that slow cell division and cause cell death. They have shown limited efficacy when used alone. ${ }^{162,163} \mathrm{~A}$ promising approach is the addition of a these agent as a third drug to a well-established regimen to obtain an additive or a synergistic effect in the so-called triple rescue regimens. A study reported, addition of panobinostrat, to either bortezomib/dexamethasone (PBD) or lenalidomide /dexamethasone (PLD) resulted in a synergistic effect in all: MM cell lines, fresh myeloma cells and plasmacytoma murine models. ${ }^{166}$ Another study also showed that PBD may be effective in relapsed and velcade refractory patients. ${ }^{167}$ The combination of panobinostat, Velcade, and dexamethasone is currently being tested in a Phase 3 clinical trial, Panobinostat is also being studied in combination with other common anti-myeloma drugs, including Revlimid, carfilzomib and pomalidomide. ${ }^{167}$ Vorinostat, another HDAC inhibitor being studied for the treatment of myeloma, was recently shown to have a small impact on PFS when used in combination with Velcade in relapsed/refractory myeloma patients. ${ }^{167}$

Bone marrow endothelial cells secrete CXCL12, also known as stromal derived factor 1-alpha (SDF-1 $\alpha$ ), which is a ligand of CXCR4 and plays a pivotal role in myeloma bone marrow homing. Thus, the CXCL12/CXCR4 stimulates motility of myeloma cell, increases the expansion and migration of plasma cells in vivo, also stimulates bone marrow angiogenesis resulting in myeloma progression. In fact, serum levels of CXCL12 correlate nicely with bone marrow angiogenesis, ${ }^{168}$ so administration of a CXCL12 antagonist will decrease angiogenesis. Martin et $a l^{168}$ reported that prolonged exposure to hypoxia and hypoxia-inducible transcription factor (HIF) strongly upregulated CXCL12 expression in myeloma plasma cells. It has been suggested that targeting HIF might be an interesting strategy in the attempt to inhibit angiogenesis and disease progression in MM.

Multiple myeloma represents the malignancy with the richest cancer/ testis antigen CTAs. CTAs are a promising class of tumor antigens and are regulated by 
epigenetic mechanisms such as promoter methylation and histone acetylation. ${ }^{169}$ Several CTAs have been detected in many MM cell lines and primary tumor samples from patients with MM and MAGE-C1/C17 was the most frequently expressed CTA in $\mathrm{MM} .{ }^{170}$ Various studies describe the role of MAGE-C1/C17 in the proliferation, disease progression, cell adhesion, chemosensitivity and apoptosis. ${ }^{171,172}$ So CTAs might constitute important targets for novel anti-myeloma specific therapies. Other molecules, monoclonal antibodies, particularly anti-IL-6 antibodies, ${ }^{173}$ AE491 ${ }^{174}$ shark cartilage compound, Arsenic trioxide ${ }^{175}$ and antibiotic Biaxin $^{174}$ is being evaluated in clinical trials at multiple centers for treatment of $\mathrm{MM}$ and are under various phases of clinical trial and once the results are confirmed, then these are likely to be incorporated in the first line treatment of myeloma.

\section{CONCLUSION}

From all the above it becomes evident that considerable progress has been made in the management of MM over the past 2 decades. From being incurable, the disease is now a chronic illness. The availability of newer drugs thalidomide, lenalidomide and bortezomib has provided an opportunity to achieve higher response rates. Initial induction therapy with these newer drugs followed by consolidation with intensive chemotherapy and ASCT in younger patients without major co-morbid condition, and combination of newer drugs with melphalan and prednisolone or dexamethasone in the elderly patients are the preferred treatment in MM patients. We can see an improved long-term outcome for patients with $\mathrm{MM}$ through several other actions /interventions like (i) the possible use of a tailored front-line therapy in an individual patient like for patients with renal failure bortezomib, thalidomide and/or doxorubicin combination could be an option, for patients with pre-existing peripheral neuropathy - lenalidomide and dexamethasone is preferred, for patients at high risk of DVT bortezomibbased regimens can be used safely ${ }^{94}$, (ii) selecting the best rescue regimens after relapse and exploiting all the effective drugs preferably in a sequential use according to previous drug exposure, depth and duration of response and previous toxicity, (iii) a careful evaluation of response, serological relapse and clinical progression ensuring a timely, appropriate administration of therapy, (iv) adequate prophylaxis and/or management of toxicities, in particular peripheral neuropathy and deep vein thrombosis and (v) supportive care. We are certain that the application of all the above will show real enhanced survival perspectives for both young and elderly patients with multiple myeloma. For the next decade we can anticipate the consolidation of the novel treatment approaches as well as the incorporation of a new generation of drugs with more specific molecular targets in myeloma treatment programs.

Funding: No funding sources

Competing interests: None declared

\section{Ethical approval: Not required}

\section{REFERENCES}

1. Munshi NC, Longo DL, Anderson KC: Plasma Cell Disorders. In: Fausi AS, Braunwald E, Kasper DL, Hauser SL, Longo DL, Jameson JL, Loscalzo J. Harrison's Principles of Internal Medicine, 17th ed., Ch. 106 New York: Mc Graw Hill; 2008. P700-6.

2. Jemal A, Siegel R, Ward E, Hao Y, Xu J, Murray T, et al. Cancer statistics 2008. CA Cancer J Clin 2008;58:71-96.

3. Hirabayashi Y, Katanoda K. Comparison of time trends in multiple myeloma incidence (1973-1997) in East Asia, Europe and United States from Cancer Incidence in Five Continents, Vols IV-VIII. Jpn J Clin Oncol 2008;38:720-1.

4. Kumar L, Vikram P, Kochupillai V. Recent advances in the management of multiple myeloma. Natl Med J India 2006;19:80-9.

5. Greenlee RT, Hill-Harmon MB, Murray T, Thun M. Cancer statistics 2001. CA Cancer J Clin 2001;51:15-36.

6. Harousseau JL, Moreau P. Autologous hematopoietic stem-cell transplantation for multiple myeloma. N Engl J Med 2009;360:2645-54.

7. Kyle RA, Gertz MA, Witzig TE, Lust JA, Lacy MQ, Dispenzieri A, et al. Review of 1027 patients with newly diagnosed multiple myeloma. Mayo Clin Proc 2003;78:21-33.

8. Kyle RA. Multiple myeloma: an odyssey of discovery. Br J Haematol 2000;111:1035-44.

9. Rajkumar SV, Kyle RA. Plasma cell disorders. In: Goldman L, Ausiello D. Cecil Textbook of Medicine. 23nd ed., Ch 198. Philadelphia: WB Saunders. p1426-37.

10. Kyle RA, Rajkumar SV. Multiple myeloma. N Engl J Med 2004;351:1860-73.

11. Cerhan JR, Cantor KP, Williamson K , Lynch CF, Torner JC, Burmeister LF. Cancer mortality among lowa farmers: recent results, time trends, and lifestyle factors (United states). Cancer causes Control 1998;9:311-9.

12. Lewis EB. Leukemia, multiple myeloma, and aplastic anaemia in American radiologists. Science1963;142:1492-4.

13. Gregersen H, Pedersen G, Svendsen N, Thulstrup AM, Sørensen HT, Schønheyder HC. Multiple myeloma following an episode of communityacquired pneumococcal bacteraemia or meningitis. APMIS 2001;109:797-800.

14. Grulich AE, Wan X, Law MG, Coates M, Kaldor JM. Risk of cancer in people with AIDS. AIDS 1999;13:839-43.

15. Gharagozloo S, Khoshnoodi J, Shokri F. Hepatitis C virus infections in patients with essential mixed cryoglobulinemia, multiple myeloma and chronic lymphocytic leukemia. Pathol Oncol Res 2001;7:135-9. 
16. An J, Lichtenstein AK, Brent G, Rettig MB. The Kaposi sarcoma-associated herpesvirus (KSHV) induces cellular interleukin 6 expression: role of KSHV latency-associated nuclear antigen and the API response element. Blood 2002;99:649-54.

17. Avet-Loiseau H, Attal M, Moreau P, Charbonnel C, Garban F, Hulin C et al. Genetic abnormalities and survival in multiple myeloma: the experience of the Intergroupe Francophone du Mye'lome. Blood 2007; 109: 3489-95.

18. Grass S, Preuss KD, Ahlgrimm M, Fadle N, Regitz E, Pfoehler C et al. Association of a dominantly inherited hyperphosphorylated paraprotein target with sporadic and familial multiple myeloma and monoclonal gammopathy of undetermined significance: A case control study. Lancet Oncol 2009;10:950-6.

19. Vachon CM, Kyle RA, Therneau TM, Foreman BJ, Larson DR, Colby CL et al. Increased risk of monoclonal gammopathy in first-degree relatives of patients with multiple myeloma or monoclonal gammopathy of undetermined significance. Blood 2009;114:785-90.

20. Lynch HT, Ferrara K, Barlogie B, Coleman EA, Lynch JF, Weisenburger D et al. Familial myeloma. N Engl J Med 2008;359:152-7.

21. Kyle RA, Therneau TM, Rajkumar SV , Offord JR, Larson DR, Plevak MF, et al. A long-term study of prognosis in monoclonal gammopathy of undetermined significance. $\mathrm{N}$ Engl $\mathrm{J}$ Med 2002;346:564-9.

22. Witzig TE. Oncogenic events. The comprehensive guide to Baniff: Understanding the VIIIth international myeloma workshop, Published by International Myeloma Foundation, USA.

23. Klein B, Zhang XG, Jourdan M, Content J, Houssiau F, Aarden L, et al. Paracrine rather than autocrine regulation of myeloma-cell growth and differentiation by interleukin-6. Blood 1989;73:51726.

24. Puthier D, Bataille R, Amiot M. IL-6 up-regulates mcl-1in human myeloma cells through JAK/STAT rather than RAS/MAP kinase pathway. Eur J Immunol 1999;29:3945-50.

25. French JD, Tschumper RC, Jelinek DF. Dissection of the signaling requirements of interleukin-6stimulated myeloma cell growth. Acta Oncol 2000;39:777-81.

26. Catlett-Falcone R, Landowski TH, Oshiro MM,Turkson J, Levitzki A, Savino R, et al. Constitutive activation of Stat 3 signaling confers resistance to apoptosis in human U266 myeloma cells. Immunity 1999;10:105-15.

27. Dispenzieri A, Lacy MQ and Greipp PR: Multiple myeloma. In:Greer JP, Rodgers GM, Foerster J, Paraskevas F. Lukens JN, Glader B. Wintrobe,s Clinical hematology, 11th ed.,Ch. 98 Philadelphia: Lippincott Williams \& Wilkins;2004. P2583-636.

28. Dankbar B, Padro T, Leo R, Feldmann B, Kropff M, Mesters RM, et al. Vascular and endothelial growth factor and interleukin-6 in paracrine tumor- stromal cell interactions in multiple myeloma. Blood 2000;95:2630-6.

29. Sezer O, Jakob C, Eucker J, Niemöller K, Gatz F, Wernecke K, et al. Serum levels of the angiogenic cytokines basic fibroblast growth factor (bFGF), vascular endothelial growth factor (VEGF) and hepatocyte growth factor (HGF) in multiple myeloma. Eur J Haematol 2001;66:83-8.

30. Jelinek DF, Witzig TE, Arendt BK. A role for insulin like growth factor in the regulation of IL-6responsive human myeloma cell line growth. J Immunol 1997;159:487-96.

31. Ge NL, Rudikoff S. Insulin-like growth factor I is a dual effector of multiple myeloma cell growth. Blood 2000;96:2856-61.

32. Hargreaves RM, Lea JR, Griffiths H, Faux JA, Holt $\mathrm{JM}$, Reid $\mathrm{C}$ et al. Immunological factors and risk of infection in plateau phase myeloma. J Clin Pathol 1995;48:260-6.

33. Nucci M, Anaissie E. Infections in patients with multiple myeloma in the era of high dose therapy and novel agents. Clin Infect Dis 2009;49:1211-25.

34. Zhou Y, Barlogie B, Shaughnessy JD Jr. The molecular characterization and clinical management of multiple myeloma in the post-genome era. Leukemia 2009;23:1941-56.

35. Dewald GW, Therneau T, Larson D, Lee YK, Fink $\mathrm{S}$, Smoley $\mathrm{S}$ et al. Relationship of patient survival and chromosome anomalies detected in metaphase and/or interphase cells at diagnosis of myeloma. Blood 2005;106:3553-8.

36. Caers J, Vande broek I, De Raeve H, Michaux L, Trullemans F, Schots R et al. Multiple myeloma: an update on diagnosis and treatment. Eur J Haematol 2008;81:329-43.

37. Katzmann JA, Clark RJ, Abraham RS, et al. Serum reference intervals and diagnostic ranges for free kappa and free lambda immunoglobulin light chains: relative sensitivity for detection of monoclonal light chains. Clin Chem 2002;48:143744.

38. Criteria for the classification of monoclonal gammopathies, multiple myeloma and related disorders:A report of the International Myeloma Working Group. Br J Haematol 2003;121:749-57.

39. Kyle RA, Rajkumar SV. Monoclonal gammopathy of undetermined significance and smouldering multiple myeloma: Emphasis on risk factors for progression. Br J Haematol 2007;139:730-43.

40. Kyle RA, Remstein ED, Therneau TM, Dispenzieri A, Kurtin PJ, Hodnefield JM et al. Clinical course and prognosis of smoldering (asymptomatic) multiple myeloma. N Engl J Med 2007;356:258290.

41. Kyle RA. Long-term survival in multiple myeloma. N Engl J Med. 1983;308:314-6.

42. Barlogie B, Jagannath S, Desikan KR, Mattox S, Vesole D, Siegel D, et al. Total therapy with tandem 
transplants for newly diagnosed multiple myeloma. Blood 1999;93:55-65.

43. Desikan R, Barlogie B, Sawyer J, Ayers D, Tricot G, Badros A, et al. Results of high-dose therapy for 1000 patients with multiple myeloma: durable complete remissions and superior survival in the absence of chromosome 13 abnormalities. Blood 2000;95:4008-10.

44. Durie BG, Salmon SE. A clinical staging system for multiple myeloma: correlation of measured myeloma cell mass with presenting clinical features, response to treatment, and survival. Cancer 1975;36:842-54.

45. Kyle RA. Prognostic factors in multiple myeloma. Stem Cells 1995;13:56-63.

46. Rapoport BL, Falkson HC, Falkson G. Prognostic factors affecting the survival of patients with multiple myeloma: a retrospective analysis of 86 patients. S Afr Med J 1991;79:65-7.

47. Greipp PR, San Miguel J, Durie BG, et al. International staging system for multiple myeloma. $\mathrm{J}$ Clin Oncol 2005;23:3412-20.

48. Gertz MA, Lacy MQ, Dispensieri A, Greipp PR, Litzow MR, Henderson KJ et al. Clinical implications of $\mathrm{t}(11 ; 14)(\mathrm{q} 13 ; \mathrm{q} 32)$, $\mathrm{t}(4 ; 14)(\mathrm{p} 16.3 ; \mathrm{q} 32)$, and $-17 \mathrm{p} 13$ in myeloma patients treated with high-dose therapy. Blood 2005;106:2837-40.

49. Zhan F, Huang Y, Colla S, Stewart JP, Hanamura I, Gupta $S$ et al. The molecular classification of multiple myeloma. Blood 2006;108:2020-8.

50. Hjorth M, Hellquist L, Holmberg E, Magnusson B, Rödjer S, Westin J. Initial versus deferred melphalan-prednione therapy for asymptomatic multiple myeloma stage I: a randomized study. Myeloma group of Western Sweden. Eur J Haematol 1993;50:95-102.

51. Riccardi A, Mora O, Tinelli C Valentini D, Brugnatelli S, Spanedda R, et al. Long term survival of stage I multiple myeloma given chemotherapy just after diagnosis or at progression of disease: a multicentre randomized study. Cooperative Group of study and treatment of multiple myeloma. $\mathrm{Br} \mathrm{J}$ Cancer 2000;82:1254-60.

52. Harousseau JL. Role of stem cell transplantation in multiple myeloma. Hematol Oncol Clin North Am 2007;21:1157-74.

53. Goldschmidt H, Hegenbart U, Wallmeier M, Hohaus S, Haas R. Factors influencing collection of peripheral blood progenitor cells following highdose cyclophosphamide and granulocyte colonystimulating factor in patients with multiple myeloma. Br J Haematol 1997;98:736-44.

54. Alexanian R, Barlogie B, Tucker S. VAD-based regimens as primary treatment for multiple myeloma. Am J Hematol 1990;33:86-9.

55. U.S Food and Drug Administration. FDA Approves Thalomid (thalidomide) to Treat Multiple Myeloma. Available http://www.fda.gov/AboutFDA/CentersOffices/Offi
ceofMedicalProductsandTobacco/CDER/ucm09565 1.htm. Accessed 25 October 2012.

56. Rajkumar SV, Hayman S, Gertz MA, Dispenzieri A, Lacy MQ, Greipp PR et al. Combination therapy with thalidomide plus dexamethasone for newly diagnosed myeloma. J Clin Oncol 2002;20:4319-23.

57. Cavo M, Zamagni E, Tosi P, Cellini C, Cangini D, Tacchetti $\mathrm{P}$ et al. First-line therapy with thalidomide and dexamethasone in preparation for autologous stem cell transplantation for multiple myeloma. Haematologica 2004;89:826-31.

58. Cavo M, Zamagni E, Tosi P, Tacchetti P, Cellini C, Cangini D, et al. Superiority of thalidomide and dexamethasone over vincristinedoxorubicindexamethasone (VAD) as primary therapy in preparation for autologous transplantation for multiple myeloma. Blood 2005;106:35-9.

59. Fermand J-P, Jaccard A, Macro M, et al. A randomized comparison of dexamethasone + thalidomide (Dex/Thal) vs Dex + Placebo (Dex/P) in patients (pts) with relapsing multiple myeloma (MM). Blood 2006;108:3563.

60. Macro M, Divine M, Uzunhan Y, Jaccard A, Bouscary D, Leblond V, et al. Dexamethasone+Thalidomide (Dex/Thal) compared to $\mathrm{VAD}$ as a pre-transplant treatment in newly diagnosed ,multiple myeloma (MM): A Randomized Trial. Blood 2006;108:57.

61. Rajkumar SV, Blood E, Vesole D, Fonseca R, Greipp PR. Eastern Cooperative Oncology Group. Phase III trial of thalidomide plus dexamethasone compared with dexamethasone alone in newly diagnosed myeloma: a clinical trial coordinated by the Eastern Cooperative Group. J Clin Oncol 2006;24:431-6.

62. Palumbo A, Falco P. New drugs in the therapy of multiple myeloma. Rev Bras Hematol 2008;30:1-7.

63. Palumbo A, Facon T, Sonneveld P, Bladè J, Offidani M, Gay F et al. Thalidomide for treatment of multiple myeloma: 10 years later. Blood 2008;111:3968-77.

64. Gay F, Palumbo A. Multiple myeloma: Management of adverse events. Med Oncol 2009;27:646-53.

65. Rajkumar SV, Hayman SR, Lacy MQ, Dispenzieri A, Geyer SM, Kabat B et al. Combination therapy with lenalidomide plus dexamethasone (Rev/Dex) for newly diagnosed myeloma. Blood 2005;106:4050-3.

66. Rajkumar SV, Jacobus S, Callander N, Fonseca R, Vesole D, Greipp P. A randomized phase III trial of lenalidomide plus high-dose dexamethasone versus lenalidomide plus low-dose dexamethasone in newly diagnosed multiple myeloma (E4A03): A Trial Coordinated by the Eastern Cooperative Oncology Group. Blood 2006;108:799.

67. Rajkumar SV, Jacobus S, Callander NS, Fonseca R, Vesole DH, Williams ME et al. Lenalidomide plus high-dose dexamethasone versus lenalidomide plus low-dose dexamethasone as initial therapy for newly 
diagnosed multiple myeloma: An open label randomised controlled trial. Lancet Oncol 2010;11:29-37.

68. U.S Food and Drug Administration FDA approves lenalidomide oral capsules (Revlimid) for use in combination with dexamethasone in patients with multiple myeloma. Available at http://www.fda.gov/AboutFDA/CentersOffices/Offi ceofMedicalProductsandTobacco/CDER/ucm09562 6.htm. Accessed 25 October 2012.

69. Kumar S, Dispenzieri A, Lacy MQ, Hayman SR, Buadi FK, Gastineau DA et al. Impact of lenalidomide therapy on stem cell mobilization and engraftment postperipheral blood stem cell transplantation in patients with newly diagnosed myeloma. Leukemia 2007;21:2035-42.

70. Mark T, Stern J, Furst JR, Jayabalan D, Zafer F, LaRow A et al. Stem cell mobilization with cyclophosphamide overcomes the suppressive effects of lenalidomide therapy on stem cell collection in multiple myeloma. Biol Blood Marrow Transplant 2008;14:795-8.

71. DiPersio JF, Stadtmauer EA, Nademanee A, Micallef IN, Stiff PJ, Kaufman JL et al. Plerixafor and G-CSF versus placebo and G-CSF to mobilize hematopoietic stem cells for autologous stem cell transplantation in patients with multiple myeloma. Blood 2009; 113:5720-6.

72. Giralt S, Stadtmauer EA, Harousseau JL, Palumbo A, Bensinger W, Comenzo RL, et al. International Myeloma Working Group (IMWG) consensus statement and guidelines regarding the current status of stem cell collection and high-dose therapy for multiple myeloma and the role of plerixafor (AMD 3100). Leukemia 2009;23:1904-12.

73. Duarte RF, Shaw BE, Marin P, Kottaridis P, Ortiz $\mathrm{M}$, Morante $\mathrm{C}$ et al. Plerixafor plus granulocyte CSF can mobilize hematopoietic stem cells from multiple myeloma and lymphoma patients failing previous mobilization attempts: EU compassionate use data. Bone Marrow Transplant 2011;46:52-8.

74. Micallef IN, Ho AD, Klein LM, Marulkar S, Gandhi PJ, McSweeney PA. Plerixafor (Mozobil) for stem cell mobilization in patients with multiple myeloma previously treated with lenalidomide. Bone Marrow Transplant 2011;46:350-5.

75. Brave M, Farrell A, Ching Lin S, et al. FDA review summary: Mozobil in combination with granulocyte colony-stimulating factor to mobilize hematopoietic stem cells to the peripheral blood for collection and subsequent autologous transplantation. Oncology 2010;78(3-4):282-8.

76. Palumbo A, Rajkumar SV. Treatment of newly diagnosed myeloma. Leukemia 2009;23:449-56.

77. Harousseau JL, Attal M, Leleu X, Troncy J, Pegourie B, Stoppa AM et al. Bortezomib plus dexamethasone as induction treatment prior to autologous stem cell transplantation in patients with newly diagnosed multiple myeloma. Haematologica 2006;91:1498-505.
78. Rosiñol L, Oriol A, Mateos MV, Sureda A, GarcíaSánchez P, Gutiérrez N et al. A phase II trial of alternating bortezomib and dexamethasone as induction regimen before autologous stem cell transplantation in younger patients with multiple myeloma: efficacy and clinical implications of tumour response kinetics. J Clin Oncol 2007;25:4452-8.

79. Richardson PG, Sonneveld P, Schuster MW, Irwin D, Stadtmauer EA, Facon $\mathrm{T}$ et al. Assessment of proteasome inhibition for extending remissions (APEX) investigators. Bortezomib or high-dose dexamethasone for relapsed multiple myeloma. $\mathrm{N}$ Engl J Med 2005;352:2487-98.

80. Richardson PG, Chanan-Khan A, Schlossman RL et al. Phase II trial of single agent bortezomib $\left(\right.$ Velcade $\left.^{\circledR}\right)$ in patients with previously untreated multiple myeloma (MM). Blood 2004;104:100a (A336).

81. Jagannath S, Durie BG, Wolf J, Camacho E, Irwin $\mathrm{D}$, Lutzky $\mathbf{J}$ et al. Bortezomib therapy alone and in combination with dexamethasone for previously untreated symptomatic multiple myeloma. $\mathrm{Br} \mathrm{J}$ Haematol 2005;129:776-83.

82. San Miguel JF, Schlag R, Khuageva NK, Dimopoulos MA, Shpilberg O, Kropff $M$ et al. VISTA Trial Investigators. Bortezomib plus melphalan and prednisone for initial treatment of multiple myeloma. N Engl J Med 2008;359:906-17.

83. Mateos MV, Hernández JM, Hernández MT, Gutiérrez NC, Palomera L, Fuertes $M$ et al. Bortezomib plus melphalan and prednisone in elderly untreated patients with multiple myeloma: Updated time-to-events results and prognostic factors for time to progression. Haematologic 2008;93:560-5.

84. Rosinol L, Cibeira MT, Martinez J, Mateos MV, Oriol A, Terol MJ et al. Thalidomide/dexamethasone (TD) vs bortezomib (velcade)/thalidomide/dexamethasone vs VBMCP/ $\mathrm{VBAD} /$ velcade as induction regimens in prior autologous stem cell transplantation (SCT) in multiple myeloma (MM): Results of a phase III PETHEMA/GEM trial. Blood 2009;114:59.

85. Palumbo A, Bringhen S, Rossi D, Ria R, Offidani M, Patriarca $F$ et al. Bortezomib, melphalan, prednisolone and thalidomide (VMPT) followed by maintenance with bortezomib and thalidomide for initial treatment of elderly multiple myeloma patients. Blood 2009;114:58.

86. Harousseau J-L, Marit G, Caillot $D$ et al. Velcade/dexamethasone (Vel/Dex) versus VAD as induction treatment prior to autologous stem cell transplantation (ASCT) in newly diagnosed multiple myeloma (MM): an interim analysis of the IFM 2005-01 randomized Multicenterphase III Trial. Blood 2006;108:56.

87. Chanan-Khan A, Sonneveld P, Schuster MW, Stadtmauer EA, Facon T, Harousseau JL et al. Analysis of herpes zoster events among bortezomib- 
treated patients in the phase III APEX study. J Clin Oncol 2008;26:4784-90.

88. Durie BG. Treatment of myeloma-are we making progress? N Engl J Med 2008;359:964-6.

89. Anderson KC, Alsina M, Bensinger W, et al. NCCN clinical practice guidelines in oncology: multiple myeloma. J Natl Compr Canc Netw 2009;7:908-42.

90. Attal M, Harousseau JL, Stoppa AM, Sotto JJ, Fuzibet JG, Rossi JF et al. A prospective, randomized trial of autologous bone marrow transplantation and chemotherapy in multiple myeloma. Intergroupe Français du Myélome. N Engl J Med 1996;335:91-7.

91. Fermand JP, Katsahian S, Divine M, Leblond V, Dreyfus F, Macro M et al. Highdose therapy and autologous blood stem-cell transplantation compared with conventional treatment in myeloma patients aged 55 to 65 years: Long-term results of a randomized control trial from the Group MyelomeAutogreffe. J Clin Oncol 2005;23:9227-33.

92. Blade J, Sureda A, Ribera JM, Mediavilla JD, Larafia JG, Palomera L et al. High dose therapy/auto transplantation/intensification versus continued conventional chemotherapy in multiple myeloma patients responding to initial chemotherapy: Definitive results from PETHEMA after a median follow up of 66 months. Blood 2003;102:42a.

93. Fermand JP, Ravaud P, Chevret S, Divine M, Leblond V, Belanger C et al. High-dose therapy and autologous peripheral blood stem cell transplantation in multiple myeloma: upfront or rescue treatment? results of a multicenter sequential randomized clinical trial. Blood 1998;92:3131-6.

94. Barlogie B, Kyle R, Anderson K, et al. Comparable survival in multiple myeloma (MM) with high dose therapy (HDT) employing MEL $140 \mathrm{mg} / \mathrm{m} 2$ + TBI 12 Gy autotransplants versus standard dose therapy with VBMCP and no benefit from interferon (IFN) maintenance: results of Intergroup Trial S9321[abstract]. Blood 2003;102:42a.

95. Rajkumar SV, Fonseca R, Lacy MQ, et al. Autologous stem cell transplantation for relapsed and primary refractory myeloma. Bone Marrow Transplant 1999;23:1267-72.

96. Blade J, Esteve J. Treatment approaches for relapsing and refractory multiple myeloma. Acta Oncol 2000;39:843-7.

97. Blade J, Vesole DH, Gertz M. High-dose therapy in multiple myeloma. Blood 2003;102:3469-70.

98. Barlogie B, Jagannath S, Vesole DH, Naucke S, Cheson B, Mattox S et al. Superiority of tandem autologous transplantation over standard therapy for previously untreated multiple myeloma. Blood 1997;89:789-93.

99. Attal M, Harousseau JL, Facon T, Guilhot F, Doyen C, Fuzibet JG et al. Single versus double autologous stem-cell transplantation for multiple myeloma. N Engl J Med 2003;349:2495-502.
100. Mehta J, Singhal S. Graft-versus-myeloma. Bone Marrow Transplant 1998;22:835-43.

101. Gahrton G, Svensson H, Cavo M, et al, European Group for Blood and Marrow Transplantation. Progress in allogenic bone marrow and peripheral blood stem cell transplantation for multiple myeloma: a comparison between transplants performed 1983-93 and 1994-8 at European Group for Blood and Marrow Transplantation centres. Br J Haematol 2001;113:209-16.

102. Kumar A, Kharfan-Dabaja MA, Glasmacher A, Djulbegovic B. Tandem versus single autologous hematopoietic cell transplantation for the treatment of multiple myeloma: A systematic review and meta-analysis. J Natl Cancer Inst 2009;101:100-6.

103. Bruno B, Rotta M, Patriarca F, Mordini N, Allione $\mathrm{B}$, Carnevale-Schianca $\mathrm{F}$ et al. A comparison of allografting with autografting for newly diagnosed myeloma. N Engl J Med 2007;356:1110-20.

104. Garban F, Attal M, Michallet M, Hulin C, Bourhis JH, Yakoub-Agha I et al. Prospective comparison of autologous stem cell transplantation followed by dose-reduced allograft (IFM99-03 trial) in high-risk de novo multiple myeloma. Blood 2006;107:347480.

105. Rosiñol L, Pérez-Simón JA, Sureda A, de la Rubia J, de Arriba F, Lahuerta JJ et al. A prospective PETHEMA study of tandem autologous transplantatin versus autograft followed by reducedintensity conditioning allogeneic transplantation in newly diagnosed multiple myeloma. Blood 2008;112:3591-3.

106. Crawley C, Iacobelli S, Björkstrand B, Apperley JF, Niederwieser D, Gahrton G. Reduced-intensity conditioning for myeloma: Lower nonrelapse mortality but higher relapse rates compared with myeloablative conditioning. Blood 2007;109:358894.

107. Rotta M, Storer BE, Sahebi F, Shizuru JA, Bruno B, Lange $\mathrm{T}$ et al. Long-term outcome of patients with multiple myeloma after autologous hematopoietic cell transplantation and nonmyeloablative allografting. Blood 2009;113:3383-91.

108. Hulin C, Facon T, Rodon P, Pegourie B, Benboubker L, Doyen $\mathrm{C}$ et al. Efficacy of melphalan and prednisone plus thalidomide in patients older than 75 years with newly diagnosed multiple myeloma: IFM 01/01 trial. J Clin Oncol 2009;27:3664-70.

109. Palumbo A, Bringhen S, Caravita T, Merla E, Capparella V, Callea V, et al. Oral melphalan and prednisone chemotherapy plus thalidomide compared with melphalan and prednisone alone in elderly patients with multiple myeloma: Randomized controlled trial. Lancet 2006;367:82531.

110. Palumbo A, Bringhen S, Liberati AM, Caravita T, Falcone A, Callea V, et al. Oral melphalan, prednisone, and thalidomide in elderly patients with 
multiple myeloma Updated results of a randomized controlled trial. Blood 2008;112:3107-14.

111. Facon T, Mary JY, Hulin C, Benboubker L, Attal M, Pegourie B, et al. Melphalan and prednisone plus thalidomide versus melphalan and prednisone alone or reduced-intensity autologous stem cell transplantation in elderly patients with multiple myeloma (IFM 99-06): A randomised trial. Lancet 2007;370:1209-18.

112. Bennet CL, Angelotta C, Yarnold PR, Evens AM, Zonder A, Raisch DW, et al. Thalidomide and lenalidomide-associated thromboembolism among patients with cancer. JAMA 2006;296:2559-60.

113. Ludwig H, Hajek R, Tothova E, Drach J, Adam Z, Labaret B, et al. Thalidomide-dexamethasone compared with melphalan-prednisolone in elderly patients with multiple myeloma. Blood 2009; 113:3435-42.

114. Palumbo A, Falco P, Falcone A, Corradini P, Di Raimondo F, Giuliani N et al. Oral revlimid plus melphalan and prednisone (R-MP) for newly diagnosed multiple myeloma: a phase I-II study. J Clin Oncol 2007;25:4459-65.

115. Richardson P, Jagannath S, Raje N, Jakubowiak A, Lonial S, Ghobrial I et al. Lenalidomide, bortezomib and dexamethasone (Rev/Vel/Dex) as front line therapy for patients with multiple myeloma (MM). Blood 2007;110:2714.

116. Badros AZ. The role of maintenance therapy in the treatment of multiple myeloma. J Natl Compr Canc Netw 2010;8:21-7.

117. Myeloma Trialists' Collaborative Group. Interferon as therapy for multiple myeloma: an individual patient data overview of 24 randomized trials and 4012 patients. Br J Haematol 2001;113:1020-34.

118. Berenson JR, Crowley JJ, Grogan TM, Zangmeister J, Briggs AD, Mills GM et al.Maintenance therapy with alternate-day prednisone improves survival in multiple myeloma patients. Blood 2002;99:3163-8.

119. Barlogie B, Tricot G, Anaissie E, Shaughnessy J, Rasmussen E, van Rhee F et al. Thalidomide and hematopoietic-cell transplantation for multiple myeloma. N Engl J Med 2006;354:1021-30.

120. Attal M, Harousseau JL, Leyvraz S, Doyen C, Hulin $\mathrm{C}$, Benboubker L, et al. Maintenance therapy with thalidomide improves survival in patients with multiple myeloma. Blood 2006;108:3289-94.

121. Spencer A, Prince HM, Roberts AW, Prosser IW, Bradstock KF, Coyle L, et al. Consolidation therapy with low-dose thalidomide and prednisolone prolongs the survival of multiple myeloma patients undergoing a single autologous stem-cell transplantation procedure. J Clin Oncol 2009;27:1788-93.

122. Palumbo A, Gay F, Falco P, Crippa C, Montefusco V, Patriarca F, et al. Bortezomib as induction before autologous transplantation, followed by lenalidomide as consolidation-maintenance in untreated multiple myeloma patients. J Clin Oncol 2010;28:800-7.
123. McCarthy P, Owzar K, Anderson K, Hofmeister CC, Hurd DD, Hassoun $\mathrm{H}$, et al. Phase III intergroup study of lenalidomide versus placebo maintenance therapy following single autologous hematopoietic stem cell transplantation (AHSCT) for multiple myeloma: CALGB 100104. Blood 2010;116:21-2.

124. Attal M, Lauwers cances V, Marit G, Caillot D, Facon T, Hulin C et al. Maintenance treatment with lenalidomide after transplantation for MYELOMA: final analysis of the IFM 2005-02. Blood 2010;116:141. Abstract 310.

125. Palumbo A, Delforge M, Catalano J, Hajek R, Kropff M, Petrucci MT et al. A Phase 3 Study evaluating the efficacy and safety of lenalidomide combined with melphalan and prednisone in patients $>65$ years with newly diagnosed multiple myeloma (NDMM): continuous use of lenalidomide vs fixedduration regimens. Blood 2010;116:273-4.

126. Schillera GJ, Liaoa M, Sohna JP, Malonea R, Bartonia K, Habtemariam B et al. Phase I/II trial of bortezomib maintenance following autologous peripheral blood progenitor cell transplantation as treatment for intermediate- and advanced-stage multiple myeloma. Biol Blood Marrow Transplant 2008;13:57. doi:10.1016/j.bbmt.2006.12.157.

127. Kastritis E, Palumbo A, Dimopoulos MA. Treatment of relapsed/refractory multiple myeloma. Semin Hematol 2009;46:143-57.

128. Singhal S, Mehta J, Desikan R, Ayers D, Roberson $\mathrm{P}$, Eddlemon $\mathrm{P}$ et al. Antitumor activity of thalidomide in refractory multiple myeloma. N Engl J Med 1999;341:1565-71.

129. Dimopoulos MA, Chen C, Spencer A, Niesvizky R, Attal M, Stadtmauer EA et al.Long-term follow-up on overall survival from the MM-009 and MM-010 phase II trials of lenalidomide plus dexamethasone in patients with relapsed or refractory multiple myeloma. Leukemia 2009;23:2147-52.

130. Mehta J, Tricot G, Jagannath S, Ayers D, Singhal S, Siegel D et al. Salvage autologous or allogeneic transplantation for multiple myeloma refractory to or relapsing after a first-line autograft? Bone Marrow Transplant 1998;21:887-92.

131. Elice F, Raimondi R, Tosetto A, D'Emilio A, Di Bona E, Piccin A et al. Prolonged overall survival with second on-demand autologous transplant in multiple myeloma. Am J Hematol 2006;81:426-31.

132. Olin RL, Vogl DT, Porter DL, Luger SM, Schuster SJ, Tsai DE, et al. Second auto-SCT is safe and effective salvage therapy for relapsed multiple myeloma. Bone Marrow Transplant 2009;43:41722.

133. de Lavallade H, El-Cheikh J, Faucher C, Fürst S, Stoppa AM, Coso D et al. Reduced-intensity conditioning allogeneic SCT as salvage treatment for relapsed multiple myeloma. Bone Marrow Transplant 2008;41:953-60.

134. Orlowski RZ, Nagler A, Sonneveld P, Bladé J, Hajek R, Spencer A et al. Randomized phase III 
study of pegylated liposomal doxorubicin plus bortezomib compared with bortezomib alone in relapsed or refractory multiple myeloma. Combination therapy improves time to progression. J Clin Oncol 2007;25:3892-901.

135. Weber DM, Chen C, Niesvizky R, Wang M, Belch A, Stadtmauer EA et al. Lenalidomide plus dexamethasone for relapsed multiple myeloma in North America. N Engl J Med 2007;357:2133-42.

136. Dimopoulos M, Spencer A, Attal M, Prince HM, Harousseau JL, Dmoszynska A et al. Lenalidomide plus dexamethasone for relapsed or refractory multiple myeloma. N Engl J Med 2007;357:212332.

137. Richardson PG, Sonneveld P, Schuster M, Irwin D, Stadtmauer E, Facon T et al. Extended follow-up of a phase 3 trial in relapsed multiple myeloma: final time-to-event results of the APEX trial. Blood 2007;110:3557-60.

138. Moehler TM, Neben K, Benner A ,Egerer G, Krasniqi F, Ho AD et al. Salvage therapy for multiple myeloma with thalidomide and CED chemotherapy. Blood 2001;98:3846-8.

139. Baz R, Walker E, Karam MA, Choueiri TK, Jawde $\mathrm{RA}$, Bruening $\mathrm{K}$ et al. Lenalidomide and pegylated liposomal doxorubicin-based chemotherapy for relapsed or refractory multiple myeloma: safety and efficacy. Ann Oncol 2006;17:1766-71.

140. Morgan GJ, Schey SA, Wu P, Srikanth M, Phekoo $\mathrm{KJ}$, Jenner $\mathrm{M}$ et al. Lenalidomide (Revlimid), in combination with cyclophosphamide and dexamethasone (RCD), is an effective and tolerated regimen for myeloma patients. $\mathrm{Br} \mathrm{J}$ Haematol 2007;137:268-9.

141. Richardson P, Siegel D, Baz R, et al. A phase $1 / 2$ multi-center, randomized, open label dose escalation study to determine the maximum tolerated dose, safety, and efficacy of pomalidomide alone or in combination with low-dose dexamethasone in patients with relapsed and refractory multiple myeloma who have received prior treatment that includes lenalidomide and bortezomib. Blood 2010;116:377-8.

142. Lacy MQ, Allred JB, Gertz MA, Hayman SR, Short $\mathrm{KD}$, Buadi $\mathrm{F}$ et al Pomalidomide plus low-dose dexamethasone in myeloma refractory to both bortezomib and lenalidomide: comparison of 2 dosing strategies in dual-refractory disease. Blood 2011;118:2970-5.

143. Schey SA, Fields P, Bartlett JB, Clarke IA, Ashan G, Knight RD et al. Phase I study of an immunomodulatory thalidomide analog, CC-4047, in relapsed or refractory multiple myeloma. J Clin Oncol 2004;22:3269-76.

144. Lacy MQ, Hayman SR, Gertz MA Short KD, Dispenzieri A, Kumar S, et al. Pomalidomide (CC4047) plus low dose dexamethasone (Pom/dex) is active and well tolerated in lenalidomide refractory multiple myeloma (MM). Leukemia 2010;24:1934-9.
145. Kuhn DJ, Chen Q, Voorhees PM, Strader JS, Shenk $\mathrm{KD}$, Sun CM et al. Potent activity of carfilzomib, a novel, irreversible inhibitor of the ubiquitinproteasome pathway, against preclinical models of multiple myeloma. Blood 2007;110:3281-90.

146. Parlati F, Lee SJ, Aujay M, Suzuki E, Levitsky K, Lorens JB et al. Carfilzomib can induce tumor cell death through selective inhibition of the chymotrypsin-like activity of the proteasome. Blood 2009;114:3439-47.

147. Siegel DS, Martin T, Wang M, Vij R, Jakubowiak AJ, Lonial S, et al. A phase 2 study of single-agent carfilzomib (PX-171-003-A1) in patients with relapsed and refractory multiple myeloma. Blood 2012;120:2817-25.

148. Kyle RA, Yee GC, Somerfield MR, Flynn PJ, Halabi S, Jagannath $S$ et al. American Society of Clinical Oncology 2007 clinical practice guideline update on the role of bisphosphonates in multiple myeloma. J Clin Oncol 2007;25:2464-72.

149. Gucalp R, Theriault R, Gill I, Madajewicz S, Chapman R, Navari R, et al. Treatment of cancerassociated hypercalcemia: double-blind comparison of rapid and slow intravenous infusion regimens of pamidronate disodium and saline alone. Arch Intern Med 1994;154:1935-44.

150. Major P, Lortholary A, Hon J, Abdi E, Mills G, Menssen HD, et al. Zoledronic acid is superior to pamidronate in the treatment of hypercalcemia of malignancy: a pooled analysis of two randomized, controlled clinical trials. J Clin Oncol 2001;19:55867.

151. Fourney DR, Schomer DF, Nader R, ChlanFourney J, Suki D, Ahrar K, et al. Percutaneous vertebroplastyand kyphoplasty for painful vertebral body fractures in cancer patients. J Neurosurg 2003;98(1, suppl):21-30.

152. Ludwig H. Prevalence, pathogenesis and treatment of anemia with erythropoietic agents in multiple myeloma. Hematol J 2005;90:10-11.

153. Garton JP, Gertz MA, Witzig TE, , Greipp PR, Lust JA, Schroeder G et al. Epoetin alfa for the treatment of the anemia of multiple myeloma: a prospective, randomized, placebo-controlled, double-blind trial. Arch Intern Med 1995;155:2069-74.

154. Dammacco F, Castoldi G, Rodjer S. Efficacy of epoetin alfa in the treatment of anaemia of multiple myeloma. Br J Haematol 2001;113:172-9.

155. Oken MM, Pomeroy C, Weisdorf D, Bennett JM. Prophylactic antibiotics for the prevention of early infection in multiple myeloma. Am $\mathrm{J}$ Med 1996;100:624-8.

156. Chapel HM, Lee M. The use of intravenous immune globulin in multiple myeloma. Clin Exp Immunol 1994;97:21-4.

157. Yussim E, Schwartz E, Sidi Y, Ehrenfeld M. Acute renal failure precipitated by non-steroidal antiinflammatory drugs (NSAIDs) in multiple myeloma. Am J Hematol 1998;58:142-4. 
158. Wu MJ, Kumar KS, Kulkarni G, Kaiser H. Multiple myeloma in naproxen-induced acute renal failure. $\mathrm{N}$ Engl J Med 1987;317:170-1.

159. Johnson WJ, Kyle RA, Pineda AA, O’Brien PC, Holley KE. Treatment of renal failure associated with multiple myeloma: plasmapheresis, hemodialysis, and chemotherapy. Arch Intern Med 1990;150:863-9.

160. Palumbo A, Rajkumar SV, Dimopoulos MA, Richardson PG, San Miguel J, Barlogie B et al. Prevention of thalidomide- and lenalidomideassociated thrombosis in myeloma. Leukemia 2008;22:414-23.

161. Gertz MA, Kyle RA. Hyperviscosity syndrome. J Intensive Care Med 1995;10:128-41.

162. Ocio EM, Mateos MV, Maiso P, Pandiella A, San Miguel JF. New drugs in multiple myeloma: mechanisms of action and phase I/II clinical findings. Lancet Oncol 2008;9:1157-65.

163. Podar K, Chauban D, Anderson KC. Bone marrow microenvironment and the identification of new targets for myeloma therapy. Leukemia 2009;23:1024.

164. U.S Food and Drug Administration. Carfilzomib. Available

at http://www.fda.gov/Drugs/InformationOnDrugs/Ap provedDrugs/ucm312945.htm. Accessed 23 October 2012.

165. Celgene Submits Pomalidomide for FDA Approval, The Myeloma Beacon Staff. Available at http://www.myelomabeacon.com/news/2012/04/26/ celgene-submits-pomalidomide-for-fda-approval/. Accessed 23 October 2012.

166. Ocio EM, Vilanova D, Atadja P, Maiso P, Crusoe E, Fernández-Lázaro $\mathrm{D}$ et al. In vitro and in vivo rationale for the triple combination of panobinostat (LBH 589) and dexamethasone with either bortezomib or lenalidomide in multiple myeloma. Haematologica 2010;95:794-803.

167. Li V. Panobinostat Combination May Be Effective In Relapsed And Velcade-Refractory Multiple Myeloma (ASH 2011). Available at http://www.myelomabeacon.com/news/2012/01/17/ panobinostat-combination-may-be-effective-inrelapsed-and-velcade-refractory-multiple-myelomaash-201. Accessed 23 October 2012.
168. Martin SK, Diamond P, Williams SA, To LB, Peet DJ, Fujii $\mathrm{N}$ et al. Hypoxia-inducible factor-2 is a novel regulator of aberrant CXCL12 expression in multiple myeloma plasma cells. Haematologica 2010;95:776-84.

169. Wischnewski F, Pantel K, Schwarzenbach H. Promoter demethylation and histone acetylation mediate gene expression of MAGE-A1, -A2, -A3, and -A12 in human cancer cells. Mol Cancer Res 2006;4:339-49.

170. Andrade VC, Vettore AL, Felix RS, Almeida MS, Carvalho F, Oliveira JS et al. Prognostic impact of cancer/testis antigen expression in advanced stage multiple myeloma patients. Cancer Immun 2008;8:2.

171. Atanackovic D, Hildebrandt Y, Jadczak A, Cao Y, Luetkens T, Meyer $\mathrm{S}$ et al. Cancer-testis antigens MAGE-C1/CT7 and MAGE-A3 promote the survival of multiple myeloma cells. Haematologica 2010;95:785-93.

172. de Carvalho F, Vettore AL, Colleoni GW. Cancer/Testis Antigen MAGE-C1/CT7: New Target for Multiple Myeloma Therapy. Clin Dev Immunol 2012;2012:257695. doi:10.1155/2012/257695.

173. A Safety and Efficacy Study of CNTO 328 in Patients with B-Cell Non-Hodgkin's Lymphoma, Multiple Myeloma, or Castleman's Disease, clinical trials.com. Available at http://clinicaltrials.gov/ct2/show/NCT00412321. Accessed 23 October 2012.

174. Anderson KC. New therapies. The comprehensive guide to Baniff: Understanding the VIIIth international myeloma workshop, Published by International Myeloma Foundation, USA. Available at

http://myeloma.org/ArticlePage.action?tabId=13\&m enuId $\% 20=96 \&$ queryPageId $=0 \&$ articleId $=149$.

Accessed 23 October 2012.

175. Qu X, Du J, Zhang C, Fu W, Xi H, Zou J, Hou J. Arsenic Trioxide Exerts Antimyeloma Effects by Inhibiting Activity in the Cytoplasmic Substrates of Histone Deacetylase 6. PLoS One 2012;7(2):e32215.doi:10.1371/journal.pone.003221 5 .

doi:10.5455/2319-2003.ijbcp20130302

Cite this article as: Gupta M, Pal RAGK, Tikoo D.

Multiple myeloma: the disease and its treatment. Int J

Basic Clin Pharmacol 2013;2:103-21. 